\title{
Hacia un patrón territorial complejo de la movilidad residencial. El caso de la Región Metropolitana de Barcelona*
}

\author{
Antonio López-Gay \\ Centre d'Estudis Demogràfics \\ tlopez@ced.uab.es
}

Recepción: 24-01-2017

Aceptación: 15-03-2017

\section{Resumen}

Los patrones territoriales de la movilidad residencial en las grandes ciudades españolas han experimentado cambios profundos en los últimos años. El nuevo escenario se aleja del modelo de desconcentración demográfica y suburbanización territorial que había sido el predominante desde la década de 1970 y que se había prolongado hasta los primeros años del siglo XXI.

Este artículo profundiza en el caso de Barcelona, donde se ha observado un descenso en la intensidad de los movimientos suburbanizadores y un aumento en la capacidad de atracción del centro hacia los residentes de las coronas metropolitanas. Algo similar ha sucedido con los centros de los subsistemas residenciales de la metrópolis, mientras que los municipios pequeños y medianos más alejados del centro dejan atrás periodos en los que crecían a un ritmo extremadamente intenso debido a la aportación de la migración. Como resultado, los orígenes y los destinos de los cambios de residencia son ahora más diversos y los modelos de suburbanización y de recentralización coexisten de una forma más equilibrada, sin olvidar la emergencia de los movimientos periferia a periferia. Todo ello en el contexto de una región metropolitana más madura, en la que la etapa de expansión territorial parece haber llegado a su fin por el descenso de la demanda endógena de vivienda, un escenario asociado a la menor generación neta de hogares y a los cambios en la estructura de la población.

Palabras clave: movilidad residencial; cambio de vivienda; suburbanización; recentralización; movilidad intramunicipal; Barcelona; crisis económica

* Este artículo se ha elaborado en el marco del proyecto de I+D+I Movilidad residencial, selección sociodemográfica y substitución de la población: ¿hacia la polarización de las ciudades españolas? MOVIPOL (CSO2014-60967-JIN) del Ministerio de Economía y Competitividad y del CERCA Programme / Generalitat de Catalunya. 
Abstract. Towards a Complex Spatial Pattern of Residential Mobility: The Case of the Metropolitan Region of Barcelona

The spatial patterns of residential mobility have experienced deep changes during the last years in the largest Spanish Metropolitan Areas. The new scenario differs from the pattern of demographic deconcentration and territorial suburbanization that had been the predominant one since the 1970s and lasted until the first years of the 21 st century.

This article explores the case of Barcelona, where a decrease in the intensity of the suburban movements and an increase of the attractiveness of the urban center towards the metropolitan residents has been observed. Something similar has happened with the centers of the residential sub-systems of the metropolis. Meanwhile, the medium and small municipalities located in suburban areas leave behind the periods in which they grew at an extraordinary positive rate due to the contribution of internal migration. As a result, the origins and the destinations of residential movements are now more diverse and suburbanization and recentralization processes coexist in a more balanced manner, not forgetting the emergence of the movements that have the origin and the destination within the suburban areas. These processes take place in the context of a more mature metropolitan region, where the period of territorial expansion seems to have come to an end, mainly due to the decline in the endogenous demand, a scenario linked to a low net creation of households and changes in the demographic structure of the population.

Keywords: residential mobility; housing change; suburbanization; recentralization; short distance migration; Barcelona; economic crisis

\section{Sumario}

1. Introducción y antecedentes

2. Caso de estudio y metodología

3. Una visión de conjunto de los cambios recientes en la dinámica residencial de la Región Metropolitana de Barcelona

4. El papel de la ciudad central en la dinámica residencial de la Región Metropolitana de Barcelona
5. La corona metropolitana y sus subsistemas residenciales. ¿Se ha frenado el proceso de desconcentración?

6. Conclusiones y reflexiones finales Referencias bibliográficas

\section{Introducción y antecedentes}

Durante las últimas décadas del siglo XX, las grandes metrópolis españolas estuvieron caracterizadas por un modelo predominante que se sintetiza en la desconcentración demográfica de los espacios centrales y en la suburbanización territorial hacia las coronas metropolitanas. Antes, la concentración de la población en los espacios centrales había sido el proceso principal, alimentado por los flujos migratorios intrarregionales e interregionales que se asentaron de forma preferente en estos ámbitos a lo largo del siglo XX. A partir de 1950, se comienza a formar y a consolidar el territorio metropolitano, con el crecimiento de las áreas funcionales y la consolidación de unos ejes metropolitanos (Nel.lo, 2004). El territorio más cercano a los espacios centrales 
fue el primero en experimentar un incremento intenso de la población y del número de hogares. Los primeros síntomas evidentes de saturación y madurez de los grandes municipios centrales españoles surgieron tras 1970, a partir de cuyo momento se registraron crecimientos mínimos de la población en las dos ciudades centrales más pobladas, Madrid y Barcelona, tan solo producto de un saldo natural positivo y elevado (López-Gay, 2014). Se agotaron los flujos interregionales y emergieron los procesos de desconcentración demográfica, dispersión urbana y expansión de las áreas funcionales (Vinuesa, 1997; Recaño, 2004; García Coll, 2005; Feria y Susino, 2012). La migración intermunicipal, con un perfil de migrante esencialmente adulto y adulto joven que busca la localización de la residencia en las coronas metropolitanas, se convirtió en el principal protagonista de la dinámica demográfica y migratoria (Módenes, 1998). Entre los aspectos que explican este proceso, destacan los siguientes:

- Elementos de naturaleza demográfica con la llegada a la edad de emancipación residencial de las generaciones del baby boom, nacidas entre 1960 y 1975, que incrementaron significativamente la demanda de vivienda en sectores urbanos (Donat, 2012; López-Gay y Mulder, 2012). En 1991, se contabilizaban hasta 10 millones de personas de la franja de edad entre 10 y 24 años en España (una cuarta parte de la población), cuya emancipación residencial era inminente.

- La revalorización de los espacios periféricos, ya fuera por la relocalización de la actividad económica, por la expansión de las vías rápidas de comunicación o por los nuevos modelos residenciales, en que se valoraban favorablemente las características de la vivienda y del entorno (Pujadas, 2005).

- La situación del mercado de la vivienda, con precios menores en las coronas metropolitanas y la capacidad de movilidad cotidiana de la población (Alberich, 2007).

Como consecuencia de estos procesos, los dos grandes municipios centrales españoles experimentaron pérdidas de población. En el caso de Barcelona, se registró un descenso desde 1,75 millones de habitantes en 1981 hasta 1,5 en 2001. En cambio, la población del conjunto de circunscripciones metropolitanas situadas a menos de 15 kilómetros del término central se estabilizó en torno a 1,25 millones, y los municipios metropolitanos localizados más allá de esta distancia aumentaron su población desde 1,25 millones hasta 1,75 en el mismo periodo. El juego de pesos poblacionales en la metrópolis cambió de forma drástica: mientras que, en 1960, casi el 55\% de la población metropolitana residía en el municipio central, en 2001, solo residían tres de cada diez habitantes de la metrópolis.

El reflejo de estas dinámicas en la morfología urbana de la conurbación barcelonesa fue muy evidente tras esta etapa. La estructura física de la metrópoli se expandió a través de tres grandes tipologías morfológicas: ambientes urbanos, paisajes de baja densidad y escenarios en red (Font, 2007). Relacionados con la proliferación de zonas de baja densidad, emergió 
con fuerza la presencia de paisajes banales, basados en la repetición y en la acentuación de una serie de espacios y elementos morfológicos propios de la urbanización dispersa y nuevos en el contexto de las ciudades mediterráneas (Muñoz, 2007).

Con el cambio de siglo, los grandes municipios centrales españoles volvieron a experimentar un aumento de población que no habían registrado desde hacía décadas. La llegada de habitantes de nacionalidad extranjera fue el artífice de esta inflexión en la evolución de la población, sobre todo en un inicio, porque, a lo largo de la década, se ha registrado evidencia empírica del incremento del atractivo de estos espacios hacia la población del resto de la Región Metropolitana (López-Gay, 2011). El auge de la atracción de las áreas centrales coincide con un progresivo desgaste del modelo suburbanizador o centrífugo que había caracterizado a las tres décadas anteriores, una dinámica que se ha observado tanto con los datos de la Estadística de Variaciones Residenciales como con los datos de la Encuesta de Condiciones de Vida y Hábitos de la Población (Nel.lo y Donat, 2014; Pujadas et al., 2014). Estas tendencias observadas en las principales ciudades españolas convergerían con los procesos de retorno de la población a los centros urbanos que muchas regiones metropolitanas de Estados Unidos y del norte y del oeste de Europa conocieron durante las últimas décadas del siglo XX (Ogden y Hall, 2000; Frey, 2005; Kabisch y Haase, 2011; Rérat, 2012; Sander, 2014) y que estaban vinculados a una nueva especialización funcional de la ciudad central (Musterd, 2006) y a su resurgencia (Cheshire, 2006; Storper y Manville, 2006). Diversos autores se han planteado si estos procesos se ajustan a la fase que Van den Berg et al. (1982) definieron como de reurbanización en su modelo del ciclo urbano. Esta etapa, que comenzaría tras una fase de suburbanización, consiste, básicamente, en la reanudación del crecimiento de la población en los centros metropolitanos tras un periodo de marcado descenso, y coincidiría, además, con la pérdida de habitantes en los anillos metropolitanos. Sin embargo, las tendencias de la gran mayoría de ciudades estudiadas apuntan a que el crecimiento en los centros ha convivido en el tiempo con dinámicas suburbanizadoras. La coincidencia temporal de diferentes fases y no la sucesión de ellas se ha afirmado como una de las grandes críticas a ese modelo (Kabisch y Haase, 2011; Gil-Alonso y Bayona, 2012; Buzar et al., 2007a y 2007b).

En el caso español, las dinámicas reurbanizadoras o recentralizadoras han coincidido en el tiempo con el estallido de la crisis económica, y se ha analizado la vinculación entre ambos procesos (Nel.lo y Donat, 2014; Pujadas et al., 2014). Entre otros aspectos, el freno a los flujos inmigratorios internacionales supuso una reducción en la generación neta de hogares y, por tanto, en la demanda al mercado suburbano de la vivienda. La llegada de generaciones cada vez menos numerosas a las edades de formación de hogar también colaboró en el mismo sentido (López-Gay, 2016). Además, se ha vinculado a este periodo recesivo la disminución de la movilidad residencial intermunicipal en las regiones metropolitanas españolas (Pujadas et al., 2016), aunque queda 
por ver si ese descenso de la movilidad residencial intermunicipal se traduce también en un debilitamiento en la frecuencia total con la que la población ha cambiado de vivienda durante el periodo de recesión económica, ya que la mayoría de trabajos no contemplan los traslados de domicilio realizados en el interior de los municipios.

\section{Caso de estudio y metodología}

El objetivo del presente artículo es profundizar en el cambio de patrón de la dinámica residencial de la Región Metropolitana de Barcelona. Para conseguirlo, el trabajo no renuncia a utilizar una perspectiva del conjunto del territorio metropolitano, con lo que superará aproximaciones previas que antes únicamente se centraban en el caso de la ciudad de Barcelona para estudiar las dinámicas recentralizadoras (López-Gay, 2011). En este artículo, analizaremos los aspectos siguientes:

1. La dinámica residencial de los municipios de los espacios centrales, para ratificar o no la existencia de procesos recentralizadores y poder observar su evolución más reciente. Incluimos el análisis por separado de los municipios de la comarca del Barcelonès con más de 100.000 habitantes (Badalona, Barcelona, L'Hospitalet de Llobregat y Santa Coloma de Gramenet). Gracias a la disponibilidad de estos datos, en el caso de Barcelona, incluiremos también la movilidad que tiene lugar en el interior de la ciudad, con el objetivo de completar la dinámica del cambio de vivienda. Podremos identificar así si su población ha cambiado con menos frecuencia de vivienda durante el periodo de recesión económica, tal y como apuntarían las tendencias de la movilidad intermunicipal.

2. El caso de los demás municipios metropolitanos que ejercen como subcentros de sus propios sistemas residenciales (Módenes, 1998), con el objetivo de poder comprobar si la tendencia a la recentralización también se ha experimentado en estos espacios. Para conseguir este objetivo, hemos analizado la dinámica residencial de los municipios de más de 100.000 habitantes y de las capitales comarcales que no alcanzan este límite poblacional. En esta selección, aparecen poblaciones que han vertebrado sus propios subsistemas residenciales entorno a ellas (Granollers, Mataró, Sabadell, Sant Feliu de Llobregat, Terrassa, Vilafranca del Penedès y Vilanova i la Geltrú).

3. La dinámica residencial de los municipios pequeños e intermedios de la Región Metropolitana de Barcelona.

El trabajo se apoya principalmente en los microdatos de la Estadística de Variaciones Residenciales del periodo 1998-2014. Esta fuente es publicada anualmente por el Instituto Nacional de Estadística y recoge todos los cambios de residencia que se producen en España y que atraviesan la frontera municipal. Como hemos comentado, el estudio también incorpora el registro de cambios 
de domicilio inframunicipales que nos ha proporcionado el Ayuntamiento de Barcelona. El objetivo es poder incluir los cambios de corta distancia y así poder llegar a contemplar todos los movimientos que implican un traslado de vivienda en un contexto residencial. Finalmente, se utilizan los datos del Padrón Continuo de la Población para el cálculo de las tasas de movilidad y del indicador sintético de migración.

\section{Una visión de conjunto de los cambios recientes en la dinámica residencial de la Región Metropolitana de Barcelona}

El patrón de desconcentración demográfica fue el predominante en la Región Metropolitana de Barcelona hasta el periodo 2003-2007. Así se observa en

Figura 1. Relación entre el número de entradas procedentes de la RMB con la población del municipio de llegada. Media anual (\%o), 1998-2014
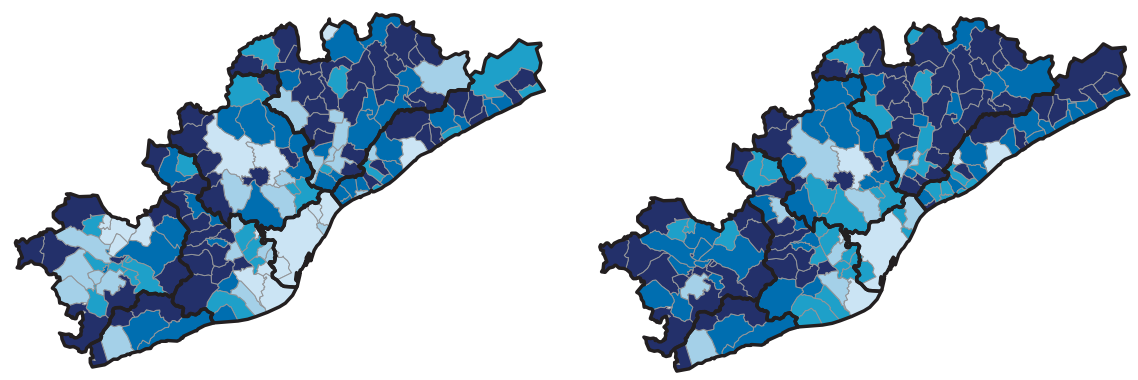

2008-2011

2012-2014
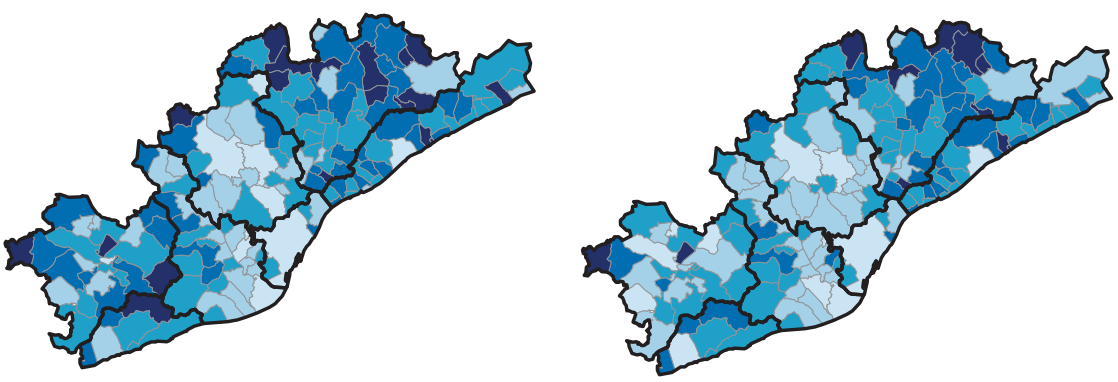

Relación inmigrantes / población municipio llegada \%o
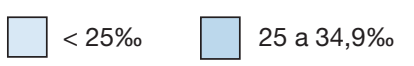

35 a $44,9 \%$

45 a $59,9 \%$

$>60 \%$

Fuente: Estadística de Variaciones Residenciales y Padrón Continuo de la Población, INE (1998-2014). 
Figura 2. Tasas de emigración con destino a la RMB. Media anual (\%), 1998-2014
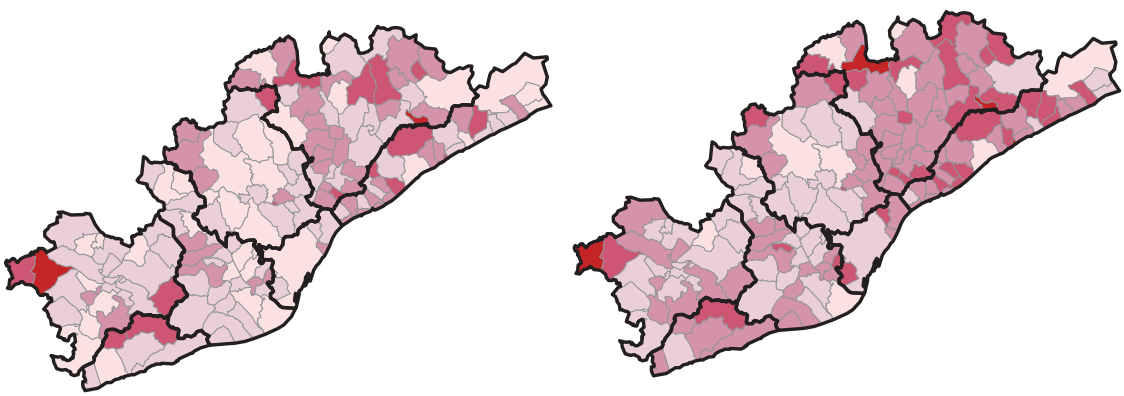

2008-2011

$2012-2014$
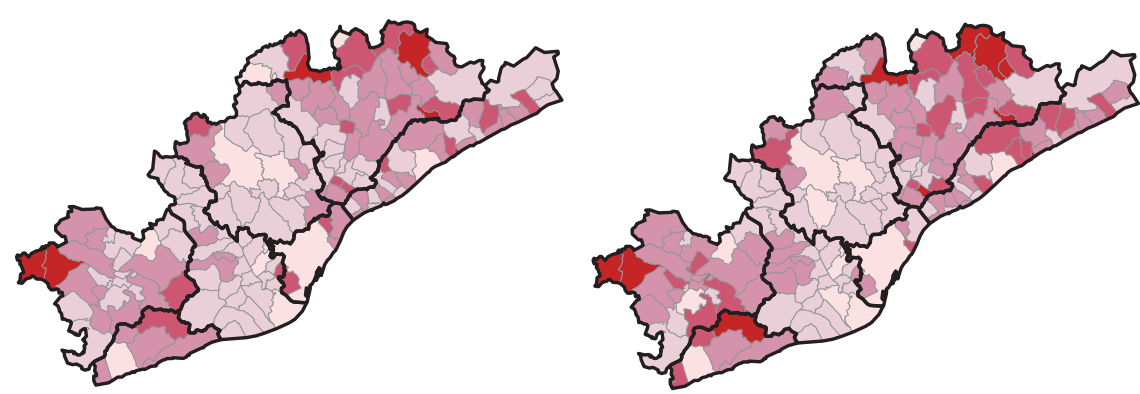

Tasas de emigración (\%o)

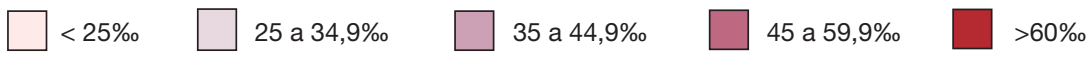

Fuente: Estadística de Variaciones Residenciales y Padrón Continuo de la Población, INE (1998-2014)

las figuras 1,2 y 3 , que presentan la intensidad relativa de los movimientos de llegada, de salida y el saldo migratorio en cada uno de los 164 municipios de la Región Metropolitana de Barcelona, siempre contabilizando únicamente los flujos residenciales que se realizan en el interior de este ámbito, es decir, con origen y destino a la RMB. De hecho, de forma general, las llegadas medias anuales del periodo 2003-2007 de los municipios metropolitanos no centrales alcanzan una intensidad no solo superior a las del periodo anterior, sino que incluso superan las alcanzadas durante las décadas de 1980 y 1990 (Módenes, 1998; López-Gay, 2008). Las altas relativas son especialmente intensas en los municipios pequeños y medianos de la segunda corona metropolitana. La mayor parte de las poblaciones situadas en estos ámbitos superan el 60\%o anual de entradas. Durante este periodo, algunos municipios centrales también presentan un número relativo de altas de cierta intensidad, como Santa Coloma de Gramenet o L'Hospitalet de Llobregat, fruto de la llegada de personas 
Figura 3. Saldo migratorio con el resto de municipios de la RMB. Media anual (\%), 1998-2014
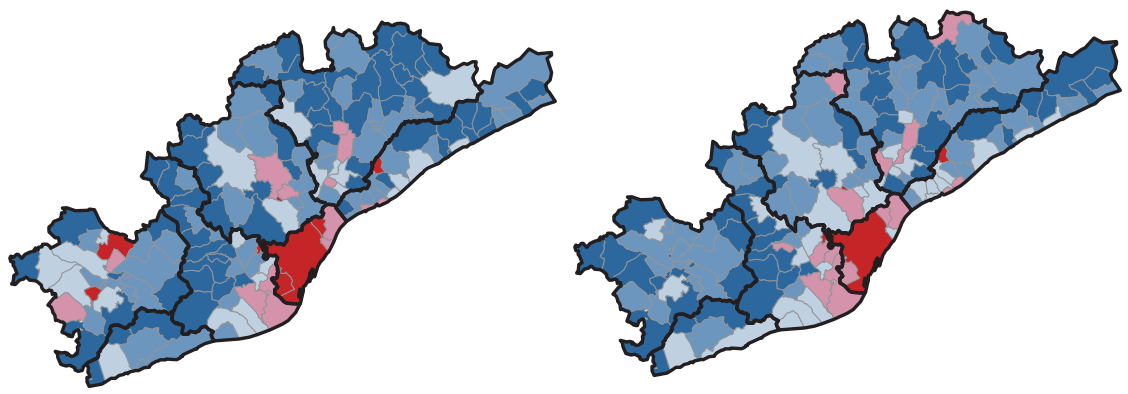

$2008-2011$

2012-2014
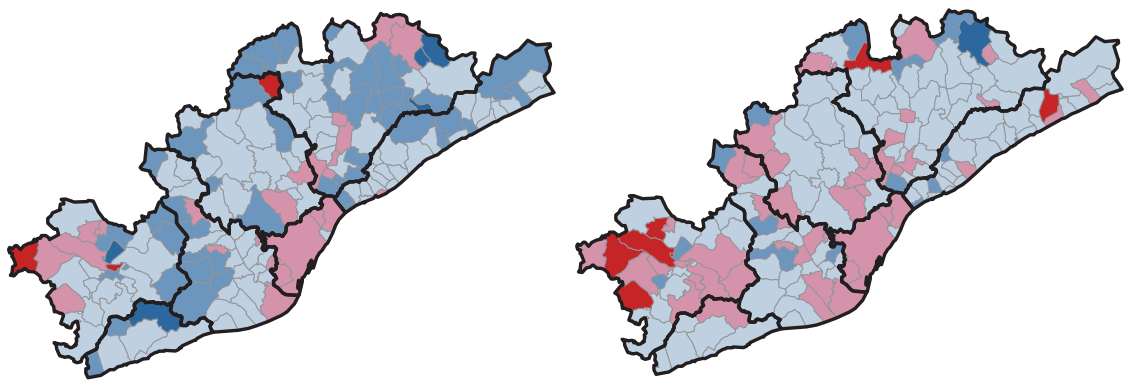

Tasas de emigración (\%)

$\square<25 \%$

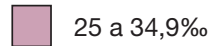

Fuente: Estadística de Variaciones Residenciales y Padrón Continuo de la Población, INE (1998-2014).

de nacionalidad extranjera procedentes de la ciudad de Barcelona (Bayona y López-Gay, 2011). El descenso de estos valores a partir del año 2008 es intenso en los municipios donde se alcanzaban los valores más altos durante los periodos anteriores, es decir, en los pequeños y medianos de la segunda corona metropolitana. En cambio, en los municipios centrales, el número relativo de altas aumenta (Barcelona y Sant Adrià de Besòs) o se estabiliza en torno a los valores de la primera mitad de la década de 2000 (Badalona, Santa Coloma de Gramenet, L'Hospitalet de Llobregat, Esplugues de Llobregat y Cornellà de Llobregat).

Las tasas de emigración municipal no han registrado unos cambios tan marcados a lo largo del periodo estudiado como en el caso de las entradas. Tan solo en el ámbito central se identifica una reducción generalizada del número de salidas. El resto de municipios metropolitanos presenta una intensidad de los cambios de residencia hacia el resto de la RMB similar a la de los periodos 
anteriores, o incluso más elevados, como es el caso de algunos municipios del Alt Penedès y del Garraf.

Como resultado de la relación entre los dos indicadores anteriores, se observan tasas de migración neta positivas muy altas en los municipios pequeños y medianos de la segunda corona metropolitana durante el periodo 1998-2007. En muchos de ellos, la diferencia media anual entre las entradas procedentes del resto de la RMB y las salidas hacia el mismo ámbito superaron con creces el $25 \%$, lo que los catapultó hacia un crecimiento de población muy intenso. En cambio, en este mismo periodo, los municipios centrales muestran los saldos migratorios negativos más intensos. En un caso similar se encuentran los municipios centrales de los diferentes subsistemas residenciales de la Región Metropolitana de Barcelona. El saldo migratorio es negativo en Sabadell o Granollers, y positivo, pero muy bajo, en Terrassa, Mataró o Vilafranca del Penedès. Estos municipios también pierden población por movilidad residencial a favor de sus entornos. En el periodo 2008-2014, la situación es muy diferente. El saldo migratorio positivo de los municipios de las coronas metropolitanas pierde intensidad de forma muy notable, sobre todo en los pequeños y medianos más alejados del centro, que, en algunos casos, incluso se convierten en negativos. En esta situación se encuentran poblaciones como Palafolls, en el Maresme; Bigues i Riells o les Franqueses del Vallès, en el Vallès Oriental; Rellinars, en el Vallès Occidental; Esparreguera, en el Baix Llobregat, o Avinyonet del Penedès, en el Alt Penedès, que han pasado de presentar tasas de migración neta positivas superiores al $20 \%$ a tenerlas negativas en un periodo muy breve de tiempo. En cambio, las pérdidas de población por movilidad residencial en los municipios centrales son cada vez menores. Mientras que, en el periodo 2003-2007, la tasa de migración neta de Barcelona era del $-11,5 \%$, en la actualidad se sitúa alrededor del $-2,5 \%$. Unas tendencias similares han experimentado municipios como Sabadell o Granollers, que han convertido en positivo el signo migratorio negativo que habían registrado en periodos anteriores.

La figura 4 sintetiza la intensidad del cambio de patrón territorial de la movilidad residencial que se ha experimentado en la Región Metropolitana de Barcelona en los últimos años. Hemos comparado el saldo migratorio medio anual del periodo más reciente, 2012-2014, con el del periodo 2003-2007, cuando las pérdidas por movilidad residencial en los municipios centrales eran máximas y las ganancias en los municipios pequeños y medios de las periferias metropolitanas, muy elevadas.

Todos los municipios centrales han experimentado una mejora de su saldo migratorio, así como también los más poblados del resto de la Región Metropolitana de Barcelona: Granollers, Sabadell, Sant Cugat del Vallès o Vilafranca del Penedès. En cambio, la práctica totalidad de los municipios metropolitanos han registrado, en el periodo más reciente, un saldo migratorio relativo notablemente inferior al del periodo 2003-2007, cuando ganaban más población por migración. El descenso del saldo migratorio ha sido especialmente intenso 
Figura 4. Diferencia en puntos del saldo migratorio anual relativo (\%) entre el periodo 20122014 y $2003-2007$

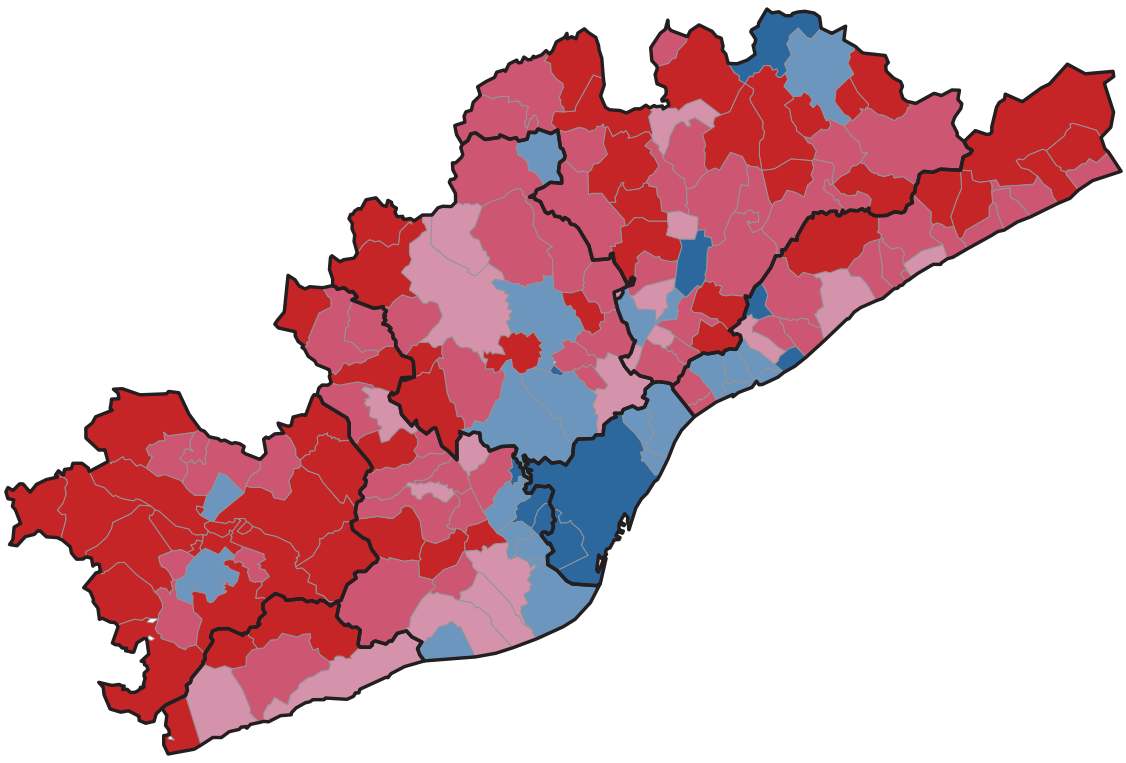

Diferencia en puntos.

Saldo migratorio anual (\%) 2012-2014 - Saldo migratorio anual (\%o) 2003-2007

$\square<-25$

25 a $-7,5$

$\square-7,5$ a 0

0 a 7,5

Fuente: Estadística de Variaciones Residenciales y Padrón Continuo de la Población, INE (1998-2014).

en los municipios pequeños y medianos los situados en la segunda corona metropolitana.

La figura 5 agrupa los datos con detalle municipal que se han visto hasta ahora en conjuntos comarcales realizados en base al tamaño de la circunscripción (el límite se ha establecido en los 50.000 habitantes, para poder aislar las dinámicas de las localidades pequeñas y medianas de las más pobladas). Así, para cada comarca de la RMB, se presentan el total de llegadas y de salidas con procedencia o destinación a la RMB que han tenido cada uno de los municipios. También se presenta el saldo migratorio total diferenciando la nacionalidad de la población, con el objetivo de observar si los procesos antes descritos tan solo existen en un grupo de población. En este caso, los datos son anuales y se puede observar con mayor precisión la evolución de los flujos mostrada hasta ahora en cuatro periodos a través de los mapas.

En la comarca del Barcelonès, donde se agrupan los municipios centrales, la suma de las salidas municipales con destino a cualquier población metropolitana (incluidas las de la misma comarca) llegó a su máximo en el año 2006, 
con más de 70.000 movimientos, a partir de cuyo momento experimentaron un descenso intenso. En 2014, este flujo se redujo más de un $25 \%$ y el total de salidas se aproxima a las 50.000. El número total de entradas procedentes de la RMB, en cambio, creció de forma intensa desde 2002 hasta 2006, cuando se estabilizó. El saldo migratorio resultante muestra el cambio de patrón residencial que se ha experimentado en la RMB en la última década. Mientras que, en los años 2003 y 2004, la comarca del Barcelonès perdía unas 30.000 personas cada año en relación con el resto de la RMB, en 2014 tan solo se han perdido unas 3.500. Tanto la población de nacionalidad española como extranjera han reducido las pérdidas del saldo migratorio en los últimos años, pero, mientras que el descenso de la española se registra a partir del 2003, el de la extranjera se experimenta a partir del 2008. Actualmente, el conjunto de los municipios del Barcelonès no pierden población extranjera por movilidad residencial con el entorno metropolitano.

La inflexión del patrón residencial que se ha experimentado en los municipios centrales durante la segunda mitad de la década del 2000 se ha registrado a la inversa en el resto del territorio metropolitano, sobre todo en el conjunto de circunscripciones de menos de 50.000 personas. En los más grandes, el número de entradas y salidas no ha experimentado, de forma general, cambios considerables. En el Baix Llobregat y en el Maresme, el saldo migratorio de los municipios más grandes continúa presentando una cifra similar de entradas y salidas. En el Vallès Occidental, la cantidad de entradas de los municipios más poblados continúa siendo ligeramente superior al de salidas, mientras que, en el Garraf, el saldo migratorio de Vilanova i la Geltrú, única localidad que supera los 50.000 habitantes, es cada vez menor. Los términos más grandes del Vallès Oriental y del Alt Penedès, en cambio, han recuperado el saldo migratorio positivo que habían perdido en algunos momentos de la primera década del 2000. En cambio, en los municipios medianos y pequeños de las comarcas metropolitanas sí se observa un patrón común definido por una fuerte reducción del elevado saldo migratorio positivo que habían registrado entre el 2000 y el 2010, que, en algunos casos, los ha llevado a presentar saldos migratorios negativos. Esta situación es fruto principalmente del marcado descenso de las entradas en estas poblaciones. En todas las comarcas, los valores máximos del saldo migratorio se alcanzaron entre el 2002 y el 2006, y los más bajos se están registrando en la actualidad. En los municipios con menos de 50.000 personas del Baix Llobregat, la ganancia por movilidad residencial en el año 2002 fue de unas 7.000 personas, mientras que la del año 2014 ha sido de unas 800. Los del Vallès Occidental ganaron 4.500 en el año 2004, y en 2014 han perdido casi 200; los del Vallès Oriental ganaron 5.000 en el año 2005, y en la actualidad, 500; los del Maresme, 4.250 en 2006, y ahora, 1.000; los del Garraf, 2.000 en 2005, y ahora apenas 100; mientras que, finalmente, los del Alt Penedès también han experimentado una inflexión en el signo del saldo migratorio, de modo que han pasado de ganar 1.750 habitantes en 2006 a perder unos 100 en el intercambio residencial con otros municipios de la RMB. 
Figura 5. Evolución de las altas, de las bajas y del saldo migratorio comarcal según el tamaño del municipio. Flujos con origen y destino a la RMB, 1998-2014

\section{Barcelonès}

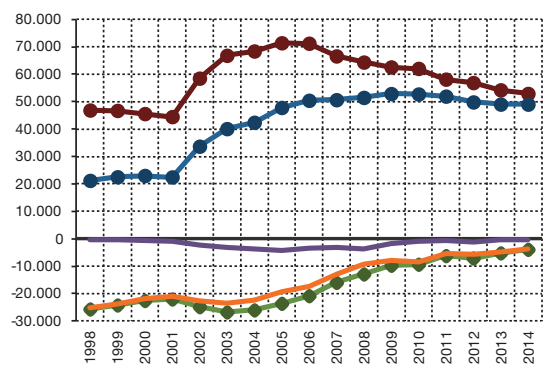

Baix Llobregat. Mayores de 50.000 hab.

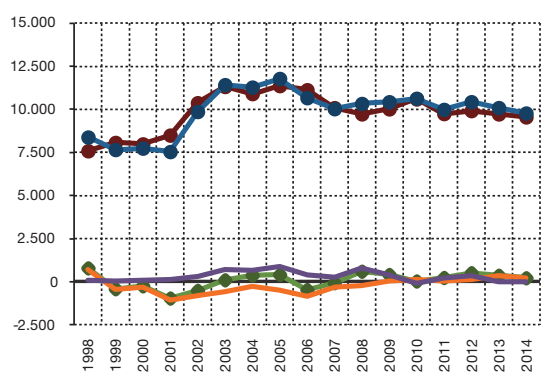

Vallès Occidental. Mayores de 50.000 hab.

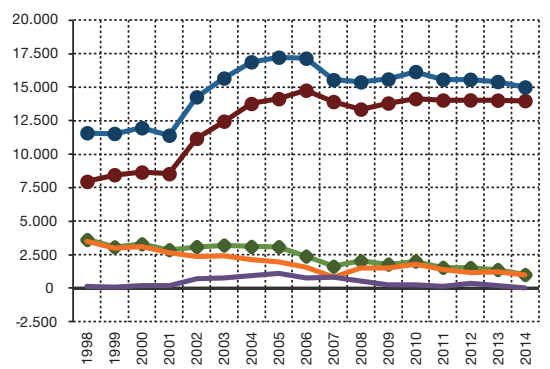

Baix Llobregat. Menores de 50.000 hab.

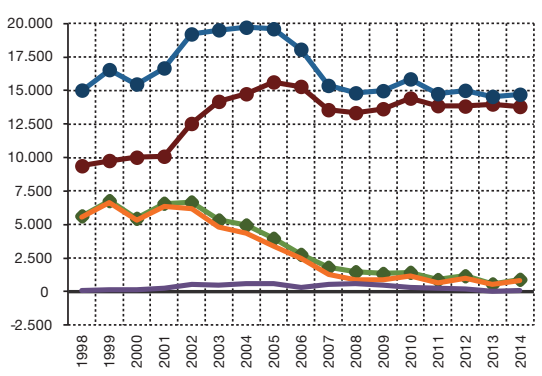

Vallès Occidental. Menores de 50.000 hab.

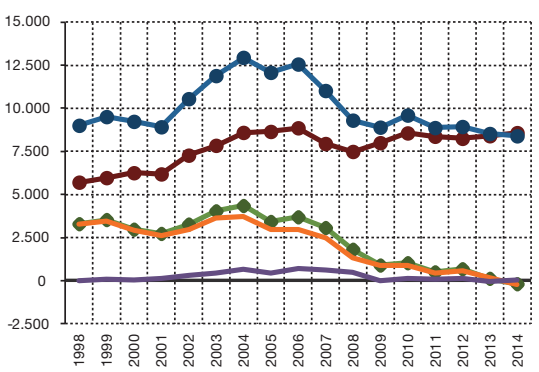

$\begin{array}{ll}\longrightarrow \text { SM total } & \longrightarrow \text { SM nacionalidad esp. } \\ \longrightarrow \text { SM nacionalidad extr. } \quad \longrightarrow \text { Salidas } & \longrightarrow \text { Entradas }\end{array}$ 
Figura 5. Evolución de las altas, de las bajas y del saldo migratorio comarcal según el tamaño del municipio. Flujos con origen y destino a la RMB, 1998-2014 (continuación)

Vallès Oriental. Mayores de 50.000 hab.

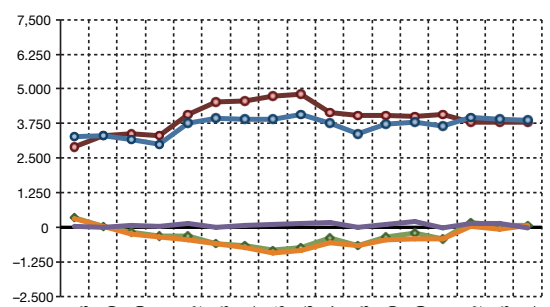

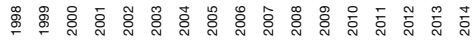

Maresme. Mayores de 50.000 hab.

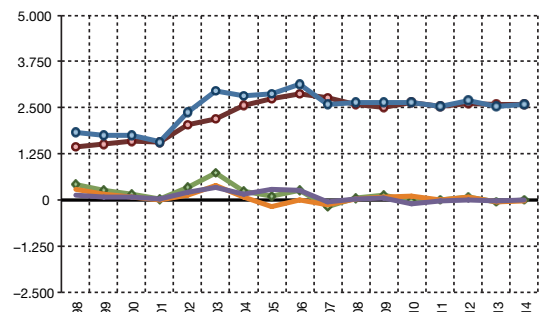

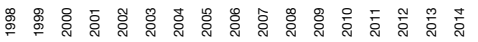

Garraf. Mayores de 50.000 hab.

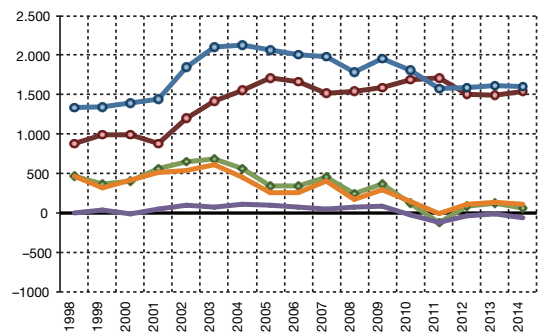

Alt Penedès. Capital (Vilafranca del Penedès)

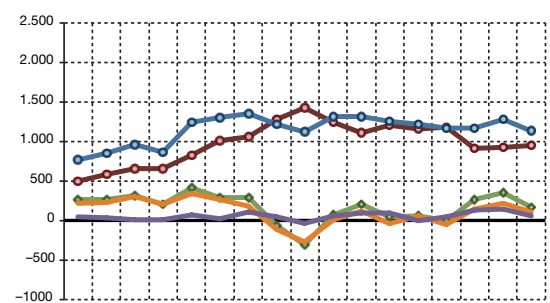

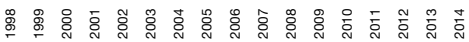

Vallès Oriental. Menores de 50.000 hab.

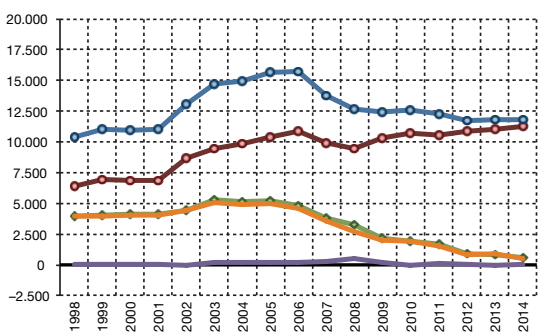

Maresme. Menores de 50.000 hab.

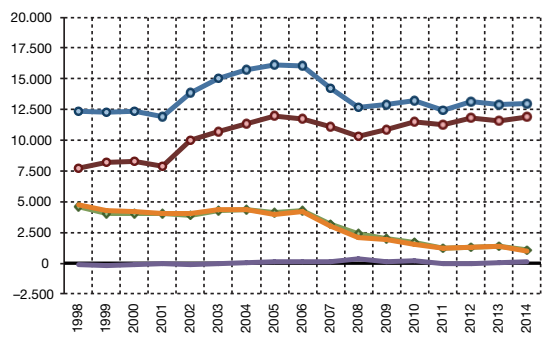

Garraf. Menores de 50.000 hab.

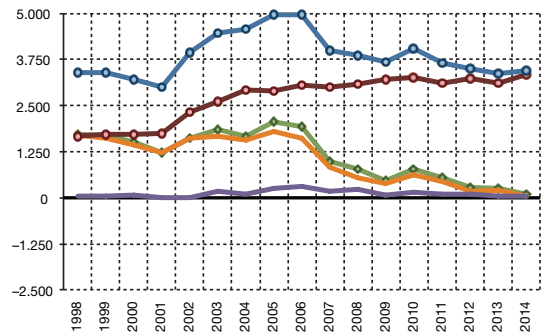

Alt Penedès. Resto de municipios

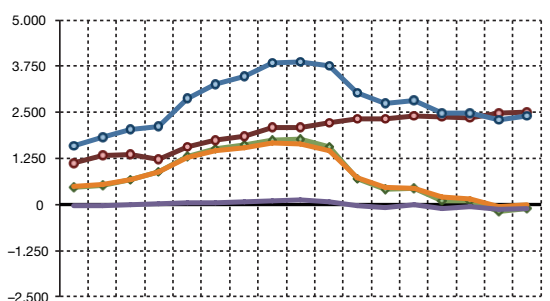

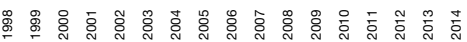

$\longrightarrow$ SM total $\quad$ SM nacionalidad esp.

Fuente: Estadística de Variaciones Residenciales, INE (1998-2014). 


\section{El papel de la ciudad central en la dinámica residencial de la Región Metropolitana de Barcelona}

¿Qué rol ha desempeñado la ciudad de Barcelona en la dinámica residencial de los últimos años? Su papel, como municipio central en la Región Metropolitana de Barcelona y como la entidad más poblada con diferencia de toda la metrópolis, es fundamental para poder confirmar o invalidar el desgaste del modelo descentralizador y la emergencia de un nuevo patrón recentralizador.

Entre 2002 y 2005 , perdió más de 20.000 personas anuales como consecuencia de los flujos residenciales. Con la llegada a la edad de emancipación de las generaciones más numerosas nacidas en la historia de la ciudad, se prolongaba y se intensificaba la tendencia que se había registrado desde los años setenta. La salida de determinados colectivos de nacionalidad extranjera también contribuyó a alcanzar dichos niveles. A partir de 2006, comenzaron a moderarse las pérdidas por movilidad residencial, una tendencia que se ha prolongado hasta el presente, sobre todo debido al descenso continuo del número de movimientos de salida de la urbe central (figura 6). La cifra de movimientos de entrada a la ciudad procedentes del resto de la RMB, en cambio, creció desde 2002 hasta 2010 y se ha estabilizado desde entonces. La reducción del saldo

Figura 6. Evolución de las altas, de las bajas y del saldo migratorio en el municipio de Barcelona. Flujos con origen y destino a la RMB, 1998-2014

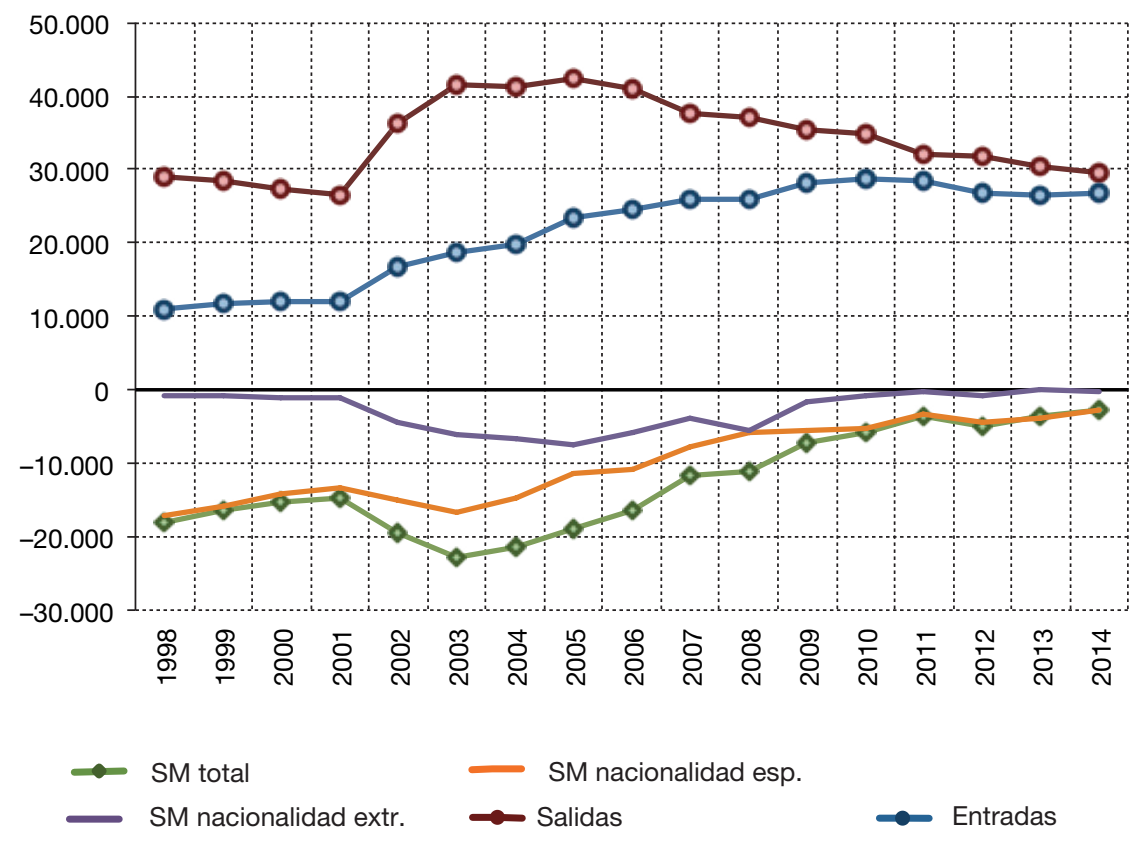

Fuente: Estadística de Variaciones Residenciales, INE (1998-2014). 
Tabla 1. Evolución de las altas, de las bajas y del saldo migratorio en el municipio de Barcelona según el ámbito territorial de relación. Media anual, 1998-2014

\begin{tabular}{llrrrr}
\hline & & $1998-2002$ & $2003-2007$ & $2008-2011$ & $2012-2014$ \\
\hline$<15 \mathrm{~km}$ & Entradas & 7.116 & 13.466 & 16.950 & 15.802 \\
& Salidas & 13.176 & 21.752 & 20.123 & 17.806 \\
& SM total & -6.060 & -8.286 & -3.173 & -2.004 \\
& SM Nac. esp. & -4.929 & -3.844 & -1.800 & -1.753 \\
& SM Nac. extr. & -1.131 & -4.442 & -1.373 & -251 \\
\hline$>15 \mathrm{~km}$ & Entradas & 5.599 & 9.029 & 10.858 & 10.885 \\
& Salidas & 16.320 & 19.043 & 14.675 & 12.766 \\
& SM total & -10.722 & -10.014 & -3.818 & -1.881 \\
& SM Nac. esp. & -10.238 & -8.426 & -3.136 & -1.846 \\
& SM Nac. extr. & -483 & -1.588 & -681 & -35 \\
\hline Resto prov. & Entradas & 752 & 1.330 & 1.604 & 1.548 \\
& Salidas & 1.627 & 2.573 & 1.993 & 1.589 \\
& SM total & -875 & -1.243 & -389 & -41 \\
& SM Nac. esp. & -819 & -1.034 & -329 & -84 \\
& SM Nac. extr. & -56 & -209 & -60 & 43 \\
\hline Resto Cat. & Entradas & 2.989 & 5.582 & 6.465 & 5.820 \\
& Salidas & 6.548 & 9.313 & 6.525 & 5.299 \\
& SM total & -3.559 & -3.731 & -60 & 522 \\
& SM Nac. esp. & -3.347 & -2.943 & -402 & 163 \\
& SM Nac. extr. & -213 & -788 & 343 & 359 \\
\hline Resto Esp. & Entradas & 7.304 & 13.767 & 16.548 & 15.260 \\
& Salidas & 8.913 & 15.342 & 14.923 & 13.425 \\
& SM total & -1.609 & -1.575 & 1.625 & 1.835 \\
& SM Nac. esp. & -1.572 & -896 & 911 & 1.466 \\
& SM Nac. extr. & -37 & -679 & 714 & 369 \\
\hline
\end{tabular}

Fuente: Estadística de Variaciones Residenciales, INE (1998-2014).

migratorio de la ciudad central por motivos residenciales no se puede atribuir únicamente al comportamiento de la población de nacionalidad extranjera. De hecho, los habitantes de nacionalidad española fueron el primer colectivo que redujo el saldo migratorio negativo desde 2003, cuando el resultado del balance de entradas y salidas con la RMB arrojó una pérdida de unas 17.000 personas. Once años después, en la misma relación residencial se han perdido 2.800 habitantes. El saldo migratorio negativo de la población de nacionalidad extranjera fue especialmente intenso durante el periodo 2002-2006, cuando el balance anual alcanzó unas pérdidas de más de 5.000 personas. Desde 2010, la pérdida de población es escasa, y en 2013 el saldo fue incluso positivo.

Las cifras totales de salidas desde la ciudad central que más se han reducido en los últimos años han sido las que tenían como destino los municipios más alejados del centro metropolitano (tabla 1). En el periodo 2003-2007, casi se registraron tantos movimientos con destino a los municipios metropolitanos 
situados a más de $15 \mathrm{~km}$ en línea recta del centro del municipio de Barcelona como hacia los más cercanos, unos 20.000 anuales. En cambio, en el periodo 2012-2014, se ha registrado una media de 13.000 a los más lejanos y de 18.000 a los más cercanos. Por otro lado, el número de entradas procedentes de los dos ámbitos ha aumentado. Como consecuencia, el saldo migratorio con las dos coronas se ha reducido muy notablemente durante el periodo estudiado. Mientras que, a comienzos del siglo XXI, se perdían 7.000 personas anuales en relación con la primera corona metropolitana y 10.000 con la segunda, en el último periodo, se ha perdido una media de 2.000 con la primera y 1.900 con la segunda. De nuevo, el descenso tan intenso del saldo migratorio en las dos coronas resulta ser un fenómeno común entre la población de nacionalidad española y en la extranjera.

La figura 7 permite profundizar en el perfil por edad de las diferencias que ya se han observado hasta ahora entre los periodos 2003-2007 y 2012-2014, que se encuentran separados por un intervalo muy corto de tiempo, pero que presentan diferencias de comportamiento muy notables. Las pérdidas de población del periodo 2003-2007 en la relación con el resto de la RMB se registraban en todos los grupos de edad, pero se concentraban en las edades adultas y adultas jóvenes, las vinculadas directamente con los procesos de emancipación residencial. Las pérdidas en la relación con la segunda corona metropolitana no se concentraban tanto en las edades de emancipación residencial como en el caso de la relación con la primera corona metropolitana. No obstante, resulta reseñable que, durante este periodo, se registraban unas pérdidas anuales de 2.500 personas de 25 a 34 años y de nacionalidad española en la relación con los municipios metropolitanos de la segunda corona. El saldo migratorio del último periodo analizado, 2012-2014, se ha reducido muy notablemente en todas las edades, tanto en la población de nacionalidad española como extranjera. En relación con la segunda corona metropolitana, se registra, incluso, un saldo migratorio positivo en la franja de 15 a 29 años. Se encuentra lejos, por tanto, de las pérdidas de población en estas edades de comienzos del siglo XXI. Donde menos se han reducido las pérdidas entre los dos periodos es en el grupo de población de más de 65 años.

En este apartado, también exploramos la relación migratoria que establece el municipio de Barcelona con el resto de la provincia, de Cataluña y de España. En la relación con el resto de la provincia de Barcelona, el saldo migratorio también se ha reducido muy notablemente, y prácticamente se ha alcanzado el saldo migratorio nulo, fruto del aumento de la cifra de entradas a Barcelona procedentes de este ámbito, pero, sobre todo, del descenso de salidas, principalmente entre la población de nacionalidad española. Mientras que, entre 2003 y 2007, el número medio anual de movimientos de este grupo hacia los municipios no metropolitanos de la provincia de Barcelona superó los 2.000, entre 2012 y 2014 , se redujeron a 1.200 , un descenso relativo muy similar al registrado en la relación con los municipios metropolitanos más alejados. Por edades, se registra en la actualidad un saldo migratorio positivo en las edades adultas jóvenes, hasta los 34 años, y se pierde población de más de 50 años. 
Figura 7. Evolución del saldo migratorio por edades en el municipio de Barcelona según el ámbito territorial de relación y nacionalidad. Media anual de los periodos 2003-2007 y 2012-2014

Municipios RMB localizados a $<15 \mathrm{~km}$

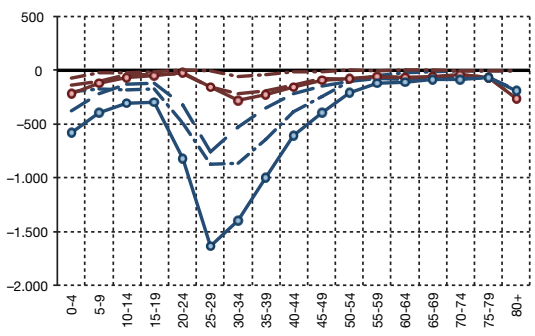

Municipios del resto de la provincia de BCN

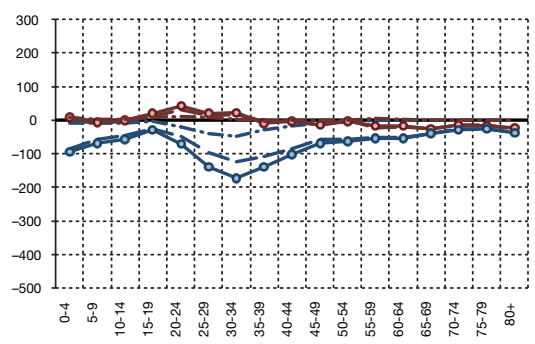

Municipios del resto de España

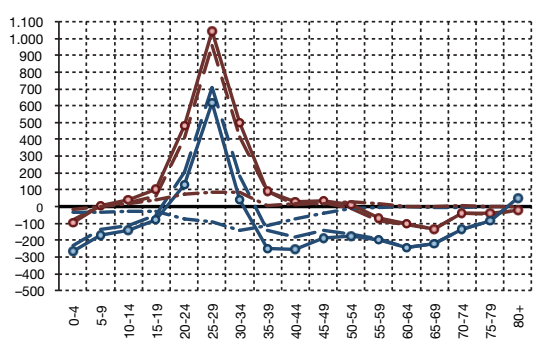

Municipios RMB localizados a $>15 \mathrm{~km}$

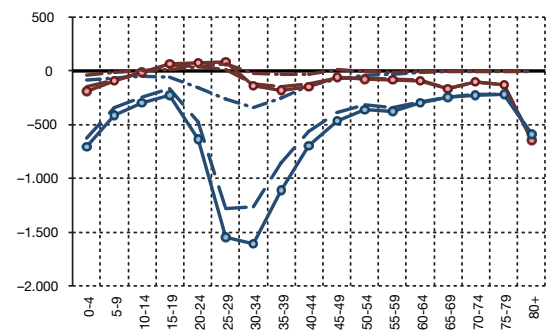

Municipios del resto de Cataluña

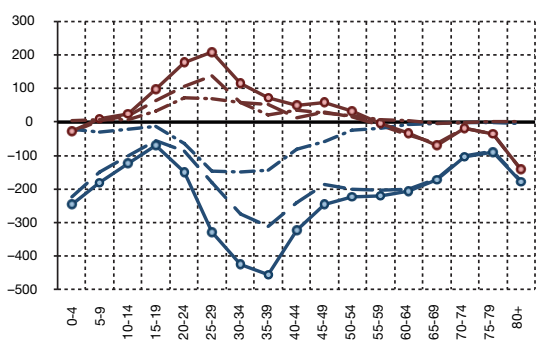

$\multimap$ SM 2003-2007 total

- - SM 2003-2007 pobl. esp.

-.... SM 2003-2007 pobl. estr.

— SM 2011-2013 total

- - SM 2011-2013 pobl. esp.

-.-.. SM 2011-2013 pobl. estr.

Fuente: Estadística de Variaciones Residenciales, INE (1998-2014).

Se ha dejado muy atrás el patrón del periodo 2003-2007, cuando se perdían más de 600 personas cada año de 25 a 44 años. En lo que respecta a la relación migratoria con el resto de Cataluña, la situación se ha invertido todavía más, ya que, de un saldo marcadamente negativo, con un balance anual de más de -3.500 personas entre 2003-2007, se ha pasado a uno positivo de más de 400 personas, una inflexión que se registra entre la población de nacionalidad española y extranjera. Por edades, se gana en la actualidad población adulta de menos de 55 años, con un pico en el grupo de 25 a 29 años, y se pierde población de edad más avanzada. Finalmente, en la relación migratoria con el 
resto de España, también se ha invertido el signo del saldo migratorio entre la población de nacionalidad española y extranjera, gracias al aumento del número total de entradas. Por edades, se han intensificado los incrementos de población de nacionalidad española en el caso de los adultos jóvenes y se han reducido las pérdidas en el resto de edades. Tan solo en personas que se encuentran en torno a la jubilación se registra actualmente un saldo migratorio negativo.

Hasta ahora, se ha enfatizado el análisis de los datos absolutos que recogen los flujos de entrada y de salida, así como el saldo migratorio de Barcelona en la relación con los diferentes ámbitos territoriales. A continuación, hemos elaborado un indicador relativo para analizar la intensidad de la movilidad residencial conservando el detalle geográfico. Los datos absolutos ofrecen una buena muestra de la dinámica residencial metropolitana, pero pueden estar afectados por diferentes aspectos, como la evolución de la población y los cambios en la estructura por edad, que podrían estar distorsionando la comparación de los valores. En el caso de la movilidad, una disminución de la población en edades de máxima movilidad residencial provocaría un descenso del número absoluto de movimientos. Proponemos la utilización del indicador sintético de migración (ISM), que controla la diversa estructura por edad de cada momento y es un índice conveniente para comparar la evolución de la intensidad del fenómeno residencial y migratorio. El ISM indica el número de movimientos residenciales que una persona realizaría durante su vida si las tasas actuales permaneciesen estables a lo largo de la misma y su cálculo es idéntico al del indicador sintético de fecundidad.

La figura 8 presenta el ISM para la movilidad residencial generada en la ciudad de Barcelona con destino al resto de municipios de la provincia según la distancia recorrida en el desplazamiento residencial, así como la generada en estos mismos ámbitos y que tiene como destino el municipio de Barcelona. En este caso, hemos creado tres categorías de municipios en función de la distancia a Barcelona, con el objetivo de precisar aún más en qué tipo de movimientos se han registrado mayores cambios. Los resultados confirman la evolución identificada a través de los saldos migratorios. Por un lado, la intensidad de las salidas residenciales se ha reducido notablemente en todos los tipos de destinos. Por el otro, la ciudad central es un destino cada vez más atractivo para los municipios metropolitanos y del resto de la provincia.

El tipo de movimiento que ha experimentado un descenso más marcado es el de los destinos metropolitanos situados a más de $20 \mathrm{~km}$ de la ciudad central: en 2003, el ISM de este tipo de movimiento era de 0,71 , mientras que una década después ha bajado hasta el 0,41 , una reducción de más del $40 \%$. La intensidad de los movimientos con destino a los municipios metropolitanos situados entre los 10 y los $19 \mathrm{~km}$ se ha reducido en un 35\%, de modo que ha pasado del 0,5 al 0,3. Los movimientos con destino a los municipios más cercanos marcaron su máximo en 2005, con un ISM de 0,92 y han experimentado un descenso del 20\%, hasta llegar al 0,75 actual.

Los habitantes del resto de la metrópolis, en cambio, incluyen cada vez más a la ciudad central en sus itinerarios residenciales, una tendencia que se registra 
Figura 8. Evolución del indicador sintético de migración de entrada y salida del municipio de Barcelona según ámbito de procedencia y destino, 1998-2014

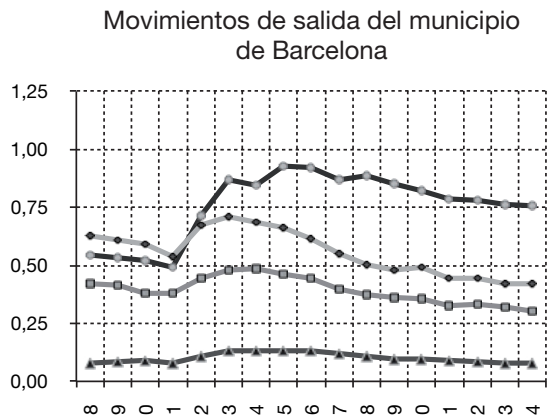

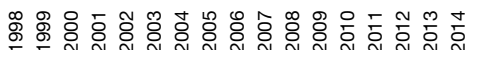

Movimientos de llegada al municipio de Barcelona

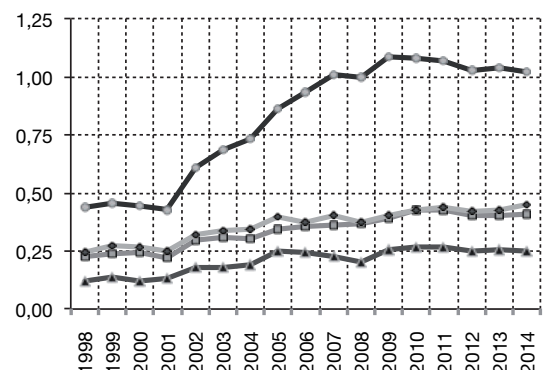

Fuente: Estadística de Variaciones Residenciales y Padrón Continuo de la Población, INE (1998-2014).

en los cuatro grupos de orígenes analizados. La intensidad de la movilidad residencial generada en el resto de la Región Metropolitana de Barcelona se ha duplicado entre 2000 y 2014, y ha pasado de 0,95 a 1,88. Desde 2010, la intensidad de movimientos con destino a Barcelona se ha estabilizado en todos los orígenes contemplados.

La realidad completa del comportamiento residencial de la población no se puede obtener si no se incorporan también al análisis los cambios de vivienda que se producen en el interior de los municipios. Pese a ser el tipo de movimiento que concentra la mayor parte de los cambios de vivienda que se realizan por motivos residenciales, raramente se han incluido en los estudios e investigaciones sobre movilidad residencial en España. El principal motivo ha sido la falta de disponibilidad de registros fiables de este tipo de flujos, que, al no atravesar ninguna frontera administrativa, no forman parte de la Estadística de Variaciones Residenciales. En los últimos años, algunos ayuntamientos han comenzado a otorgar un elevado grado de fiabilidad al registro de cambios intramunicipales y ponen al alcance de los investigadores datos agregados de este tipo de flujos. Este es el caso de Barcelona, que ha proporcionado datos desde el año 2000 hasta el 2014.

La incorporación de estos datos al análisis permite responder una pregunta clave para entender el descenso de la intensidad de los movimientos hacia las coronas metropolitanas: ¿̇la reducción de los movimientos suburbanizadores, ha sido el resultado de un descenso generalizado de la intensidad de la movilidad residencial? Es decir, ¿̇la población abandona menos la ciudad central porque cambia de residencia con menos frecuencia? o, en cambio, ¿la población no ha modificado los patrones de intensidad de la movilidad residencial y sí los patrones territoriales del fenómeno?

A priori, el periodo de coyuntura económica desfavorable podría haber ejercido efectos de signo contrario en la intensidad de la movilidad residencial. Por un lado, el propio empeoramiento económico de las familias, el 
descenso de los ingresos y de la capacidad de ahorro podrían haber actuado como freno de los proyectos residenciales. La coyuntura económica puede hacer percibir el cambio de domicilio como una decisión arriesgada, sobre todo si se contempla la adquisición de la vivienda en dicha estrategia. En este sentido, se podría pensar en un retraso de la emancipación residencial o en la posposición de proyectos de reajuste residencial, unos elementos que no contribuirían a facilitar un buen funcionamiento de la cadena de vacantes (el potencial comprador de una vivienda no la podrá adquirir hasta que no venda la anterior). El endurecimiento de las condiciones de los créditos hipotecarios tampoco tendría un efecto positivo en la movilidad residencial, como tampoco lo tienen el propio proceso de asentamiento de la población de nacionalidad extranjera en el territorio, que en muchos casos hace ya más de una década que llegó. Por otro lado, aparecen algunos elementos que podrían hacer pensar en ingredientes potenciadores de la movilidad residencial durante el periodo de recesión económica. El mercado del arrendamiento ha experimentado una expansión intensa y es conocido que las personas que viven en alquiler presentan una movilidad residencial más elevada (Módenes y López-Colás, 2014). También se podría pensar en un mayor desplazamiento como consecuencia de la necesidad de ajustar la residencia a la nueva situación económica, un escenario que afectaría de forma más intensa a los colectivos más vulnerables. En este sentido, y como consecuencia del fuerte descenso de los precios en la mayor parte de ámbitos metropolitanos, se puede pensar también en hogares que hayan cambiado de vivienda porque hayan crecido las posibilidades de encontrar alquileres más baratos o porque algunas zonas de la ciudad que antes presentaban precios elevados se hayan convertido en más asequibles. Finalmente, también se ha de pensar que, en los últimos años, han crecido los hogares más complejos, como los pisos de estudiantes, que presentan una mayor movilidad residencial (Pagès, 2015).

Así pues, podrían existir dinámicas de signo contrario en cuanto al efecto de la crisis económica en la movilidad residencial. La figura 9 añade la evolución de la intensidad de la movilidad intramunicipal a la dinámica de la movilidad residencial intermunicipal en la RMB que se había presentado anteriormente y muestra el resultado de la comparación entre la intensidad de cada tipo de movimiento entre el periodo 2003-2006, que corresponde a un momento de expansión económica, con el de 2011-2014, un periodo recesivo tras el estallido de la crisis. En este caso, también se ha añadido la nacionalidad de la población para aislar su efecto en el comportamiento residencial. Los flujos con destino a los municipios localizados a más de $10 \mathrm{~km}$ del centro de Barcelona son los que experimentan una reducción más intensa entre la población de nacionalidad española durante el periodo analizado. En los dos casos, el descenso ha sido superior al 30\%. Solo la movilidad con destino a los municipios limítrofes ha permanecido con una intensidad similar o ligeramente superior. En el caso de la población extranjera, los tres ámbitos territoriales de relación analizados han experimentado una clara disminución, superior al 30\%. La intensidad de la movilidad intramunicipal, en cambio, muestra un aumento 
Figura 9. Evolución del indicador sintético de migración en los cambios de domicilio generados en el municipio de Barcelona (incluidos los intramunicipales), según el ámbito territorial de relación y nacionalidad, 2000-2014

Población de nacionalidad española

Variación 2011-2014 vs.

2003-2006 (\%)

Destino:

$<10 \mathrm{~km}:+4,6 \%$

$10-19 \mathrm{~km}:-30,3 \%$

>20 km: $-35,3 \%$

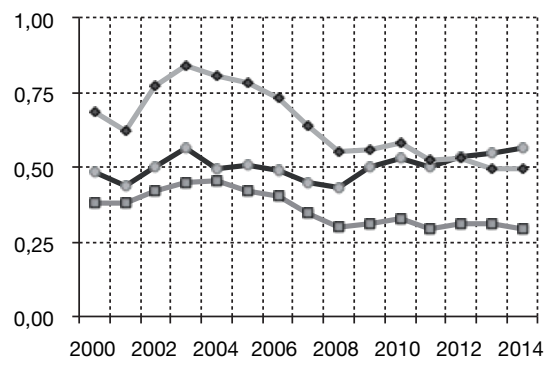

Intramunicipal: $+17,5 \%$

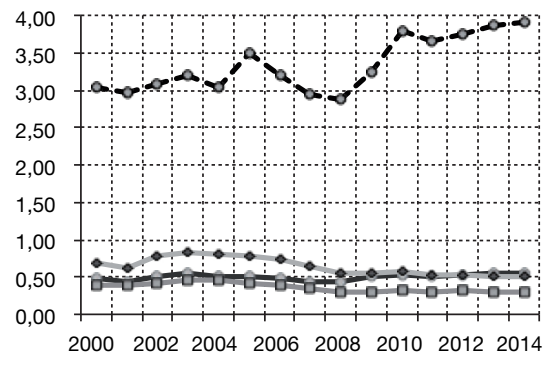

Total: $+3,7 \%$

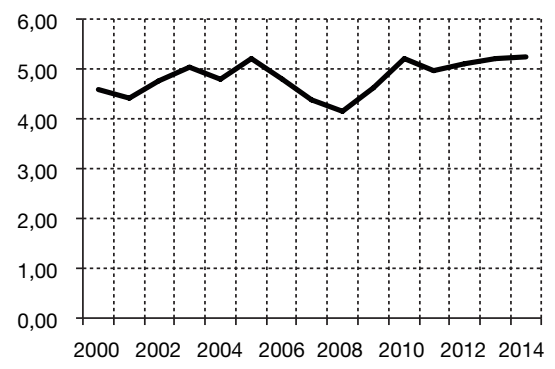

Población de nacionalidad extranjera Variación 2011-2014 vs.

2003-2006 (\%)

Destino:

$<10 \mathrm{~km}:-36,8 \%$

10-19 km: $-38,0 \%$

$>20 \mathrm{~km}:-35,1 \%$

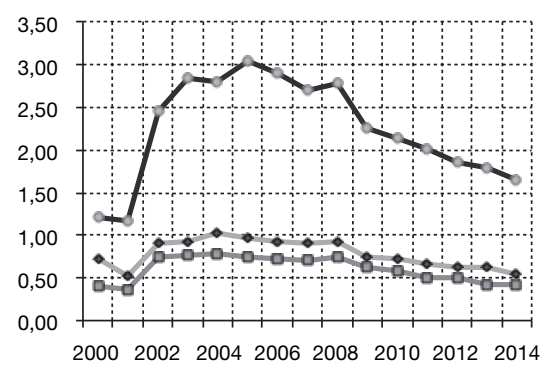

Intramunicipal: $+16,3 \%$

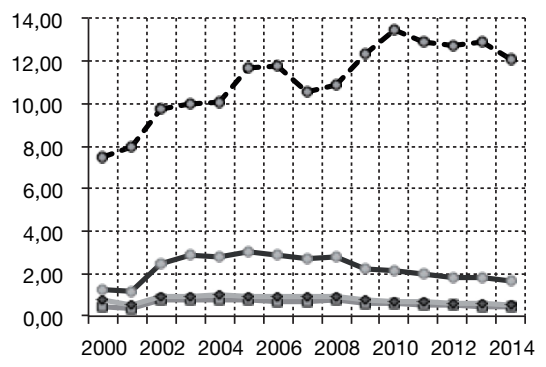

Total: $+0,5 \%$

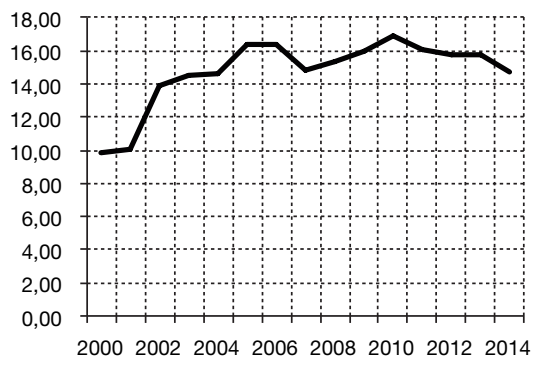

$\longrightarrow<10 \mathrm{~km} \rightarrow-10-19 \mathrm{~km} \longrightarrow 20 \mathrm{~km} \quad \longrightarrow-$ Inframunicipal $\longrightarrow$ ISM total

Fuente: Estadística de Variaciones Residenciales y Padrón Continuo de la Población, INE (2000-2014) y Registro de Cambios de Domicilio Intramunicipal, Ajuntament de Barcelona (2000-2014). 
significativo (de más del 15\%), tanto para la población de nacionalidad española como para la extranjera. La población del centro metropolitano, pues, permanece cada vez más en la ciudad central, sea de nacionalidad española o extranjera. Comparando los indicadores de intensidad de los diferentes ámbitos, se desprende que mientras, en el primer periodo, el 65\% de la población de nacionalidad española y el $70 \%$ de la extranjera permanecía en la ciudad tras cambiar de vivienda entre 2003 y 2006, en el periodo más reciente, estos valores alcanzan el $75 \%$ y el $81 \%$, respectivamente.

Solo a través de la suma de la movilidad intramunicipal y de la intermunicipal realizada en el contexto metropolitano podemos observar el cuadro completo de los cambios de vivienda que se generan en la ciudad de Barcelona y que finalizan su itinerario en el interior de la región metropolitana. Gracias al aumento de la frecuencia con que los barceloneses cambian de residencia en el interior de la ciudad, la tasa de cambio de vivienda total del periodo 2011-2014 es hasta un 3,7\% superior a la de 2003-2006 para el caso de la población de nacionalidad española. La intensidad del cambio de residencia total experimentó un descenso notable en el momento en que estalló la crisis económica, pero se ha recuperado y se ha estabilizado a partir de 2010 en torno a los valores que se registraban antes de 2007. Los resultados demuestran, pues, que la caída de la movilidad residencial intermunicipal con destino a la Región Metropolitana de Barcelona no es consecuencia del descenso de la frecuencia con que los barceloneses cambian de vivienda, sino producto de una modificación de patrones territoriales. Por lo que respecta a la población de nacionalidad extranjera, la frecuencia con la que se traslada de vivienda se ha mantenido en valores muy similares, aunque la tendencia de los años más recientes parece apuntar hacia una mayor estabilidad residencial de este colectivo.

\section{La corona metropolitana y sus subsistemas residenciales. ¿Se ha frenado el proceso de desconcentración?}

¿Se registran procesos similares a los de la ciudad central en el resto de las grandes circunscripciones de la Región Metropolitana de Barcelona? En este apartado, se analizan las dinámicas residenciales de las poblaciones de más de 100.000 habitantes y de las capitales comarcales que no alcanzan dicho umbral poblacional. De esta manera, obtenemos un dibujo más completo del escenario metropolitano y podemos profundizar en el comportamiento residencial del resto de los grandes municipios del centro metropolitano, así como en las ciudades que también habían generado su propio subsistema residencial con su entorno territorial (Módenes, 1998). Centraremos nuestro interés en averiguar si el freno a las dinámicas de desconcentración se ha producido también en esos otros subcentros metropolitanos.

La figura 10 muestra el saldo migratorio absoluto de los diez municipios escogidos (por orden de población: L'Hospitalet de Llobregat, Badalona, Terrassa, Sabadell, Mataró, Santa Coloma de Gramenet, Vilanova i la Geltrú, Granollers, Sant Feliu de Llobregat y Vilafranca del Penedès) en relación con 
Figura 10. Evolución del saldo migratorio según el ámbito territorial de relación. Flujos con origen y destino a la RMB de los municipios seleccionados, 1998-2014

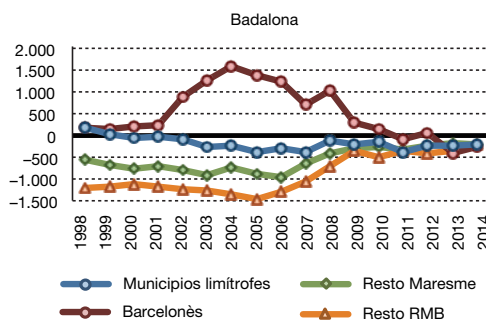

L'Hospitalet de Llobregat

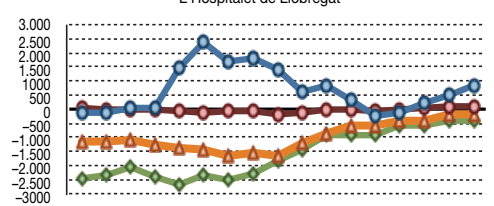

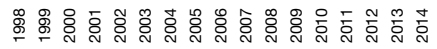

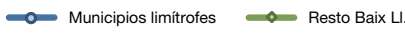

$\longrightarrow$ Barcelonès $\quad \longrightarrow$ Resto RMB

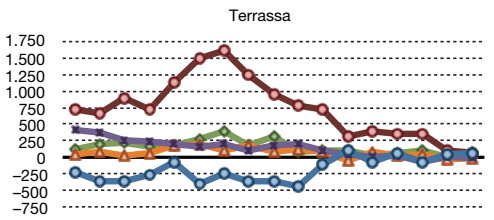

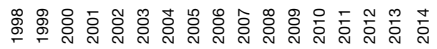
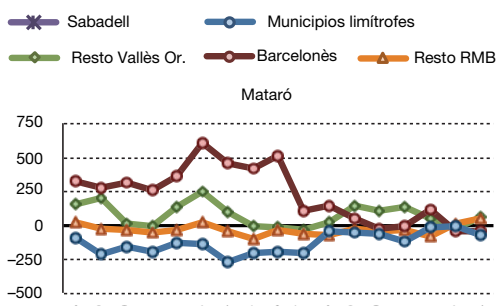

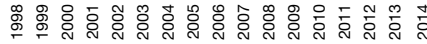

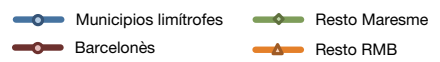

Vilanova i la Geltrú

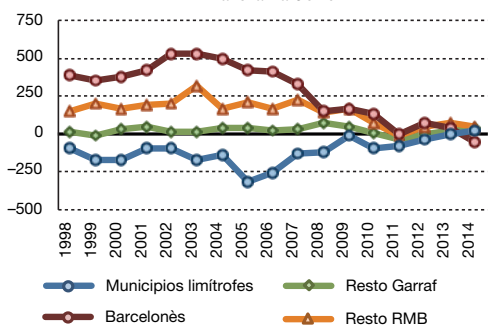

Santa Coloma de Gramanet

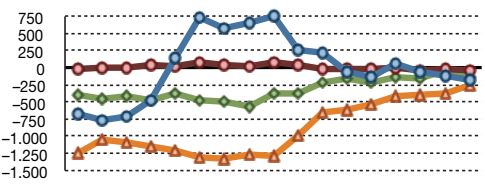

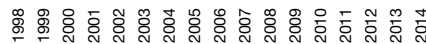

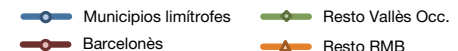

Sant Feliu de Llobregat

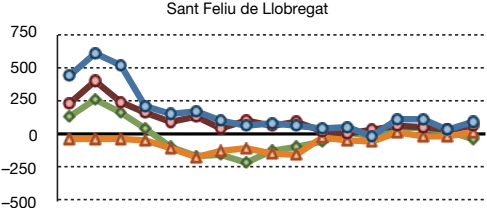

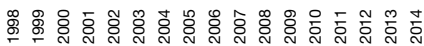
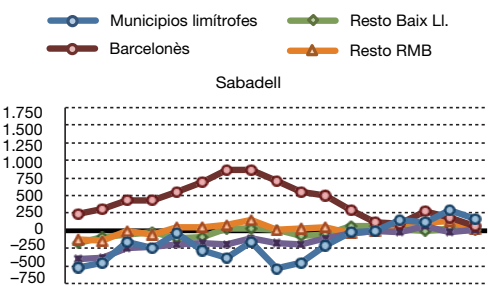

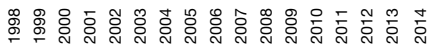
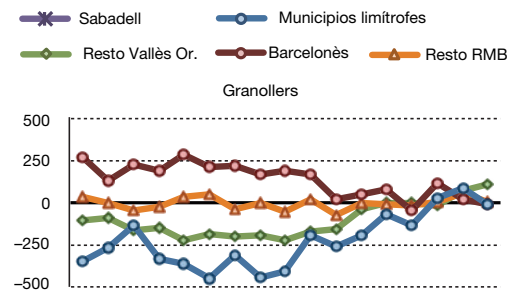

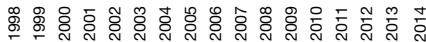

$\rightarrow$ Municipios limítrofes $\leadsto$ Resto Vallès Or.

$\rightarrow$ Barcelonès $\quad \triangle$ Resto RMB

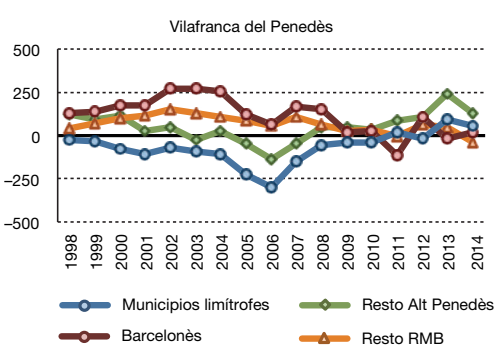

Fuente: Estadística de Variaciones Residenciales y Padrón Continuo de la Población, INE (2000-2014) y Registro de Fuente: Estadística de Variaciones Residenciales, INE (1998-2014). 
los respectivos municipios con los que hacen frontera, el resto comarcal, el Barcelonès y el resto de la RMB.

Los tres grandes municipios centrales analizados (Badalona, L'Hospitalet de Llobregat y Santa Coloma de Gramenet) han reducido de forma muy notable el saldo migratorio negativo con las poblaciones de las coronas metropolitanas, una tendencia paralela a la que se ha registrado en la ciudad de Barcelona. En todos los casos, el punto de inflexión se registró entre 2004 y 2006, y el saldo residencial con las coronas metropolitanas se redujo en más del 75\%. En L'Hospitalet de Llobregat, por ejemplo, se registraban pérdidas de 4.200 habitantes en el año 2004, y en el 2014 eran de menos de 500. Por otro lado, en los tres municipios, se registraron fuertes saldos migratorios positivos durante el periodo 2002-2008 en la relación con el resto del Barcelonès como consecuencia de la llegada de personas de nacionalidad extranjera procedentes de Barcelona. Como municipio de la primera corona metropolitana, Sant Feliu de Llobregat registró saldos migratorios positivos en relación con los espacios centrales a finales de la década de 1990 y a comienzos de la del 2000, pero se redujeron rápidamente, justo cuando comenzaron a aumentar las pérdidas en la relación con los municipios situados a más distancia del centro metropolitano. En la actualidad, el saldo entre entradas y salidas está equilibrado con todos los ámbitos contemplados.

Los otros municipios metropolitanos incluidos en este apartado, con una población de más de 100.000 habitantes y/o capitales comarcales, también han experimentado una reducción del saldo migratorio negativo que todos ellos presentaban durante el primer quinquenio del siglo XXI con las circunscripciones limítrofes. Se reproduce así, entre los subcentros de la Región Metropolitana de Barcelona, la tendencia de los municipios del centro metropolitano. Sabadell, Terrassa, Granollers y Vilafranca del Penedès incluso han registrado, desde 2013, un balance positivo en la relación residencial con sus vecinos, mientras que, en Mataró y Vilanova i la Geltrú, las salidas y las entradas con ese entorno más cercano se han equilibrado. Por otro lado, todas esas ciudades habían registrado un saldo migratorio positivo con el conjunto de municipios centrales durante los primeros años del 2000, que también se ha reducido notablemente hasta llegar al equilibrio entre las salidas y las llegadas. El hecho de que sus saldos migratorios totales en la relación con el conjunto de la RMB no hayan variado prácticamente a lo largo del periodo estudiado no puede esconder los profundos cambios que estos municipios también han conocido en los años más recientes: ya no pierden población en comparación con sus vecinos por razones residenciales ni ganan en la relación residencial con los espacios metropolitanos centrales.

Con el objetivo de ir más allá de los datos absolutos y de poder comparar la evolución de la intensidad de los cambios residenciales según el ámbito de destino o de procedencia durante el periodo estudiado, hemos calculado, también para los municipios seleccionados, el indicador sintético de migración (ISM), que controla las variaciones en el tiempo de la estructura por edad.

La intensidad de los movimientos generados en los municipios centrales con destino al resto de la RMB ha experimentado una reducción muy notable 
a partir del segundo quinquenio de la década del 2000. En L'Hospitalet de Llobregat, por ejemplo, los movimientos con destino a los municipios del Baix Llobregat se han reducido a más de la mitad entre los primeros años de la década del 2000 y la actualidad. En Badalona, se ha registrado un proceso idéntico en los movimientos con destino al conjunto de municipios del Maresme y a las demás comarcas metropolitanas no centrales. En Santa Coloma, también se observa el mismo patrón: la intensidad de los movimientos suburbanizadores se ha reducido casi a la mitad. En cambio, la intensidad de los movimientos con destino al resto de municipios del Barcelonès creció rápidamente a lo largo de la primera década del 2000 y se ha estabilizado o reducido ligeramente desde el 2010, en una tendencia en que la participación de la población de nacionalidad extranjera ha desempeñado un papel importante.

En cuanto a la atracción residencial de estos municipios sobre el resto de poblaciones metropolitanas, se observa que se mantiene la atracción respecto a sus vecinos de los espacios centrales y que aumenta ligeramente la atracción que ejercen a otras localidades de la RMB. A modo de ejemplo, las del Baix Llobregat han aumentado en un 50\% la intensidad con la que se desplazan a L'Hospitalet de Llobregat entre 2005 y 2014. También se observa, en todos los municipios centrales, un aumento de la atracción generada sobre los municipios del resto de la provincia de Barcelona.

En las grandes poblaciones metropolitanas, se confirma el descenso marcado de la intensidad de los movimientos con destino a su entorno más cercano desde la primera mitad de la década de 2000. En algunos casos, como en Sabadell, Mataró o Vilafranca del Penedès, el ISM con destino a los municipios limítrofes se ha reducido en más de un $50 \%$. En Vilafranca del Penedès, por ejemplo, se ha pasado del 0,95 en el año 2006 al 0,4 en el año 2014. En todos los casos, también se ha reducido de forma intensa la movilidad residencial con destino a las otras localidades comarcales no limítrofes. En cambio, la población de los municipios metropolitanos estudiados incorpora cada vez más los espacios centrales en sus itinerarios residenciales. En la mayoría de los casos, el ISM con destino al Barcelonès se ha doblado entre comienzos del 2000 y la actualidad. Así, en Sabadell y Terrassa, por ejemplo, el ISM con destino al Barcelonès ha aumentado del 0,2 al 0,45 entre el 2002 y el 2014. Es importante evidenciar también que, en todos los casos, se ha incrementado la movilidad con destino a otros municipios de la RMB que no pertenecen a la misma comarca ni a los entornos inmediatos. Aumenta, pues, la complejidad de la dinámica residencial de los subcentros metropolitanos: mientras que, a comienzos del 2000, el modelo residencial preponderante era la salida hacia las poblaciones más cercanas, en la actualidad se han ampliado los destinos residenciales y comparten protagonismo los movimientos que finalizan su recorrido en los municipios del entorno, en los centrales de la RMB y en otros ámbitos del territorio metropolitano. La evolución de la proporción de movimientos que no finalizan su recorrido en las poblaciones limítrofes es un claro indicador del aumento de la complejidad del patrón territorial de la movilidad residencial en estos municipios. En todos se produce un incremento de estos 
Figura 11. Evolución del saldo migratorio según el ámbito territorial de relación. Flujos con origen y destino a la RMB de los municipios seleccionados, 1998-2014
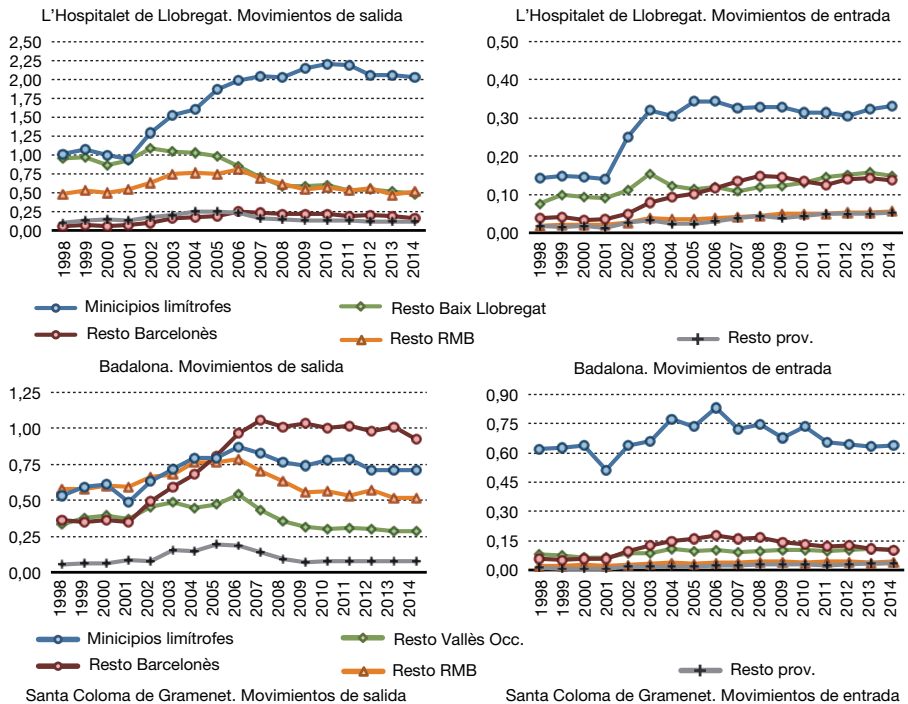

Santa Coloma de Gramenet. Movimientos de entrada

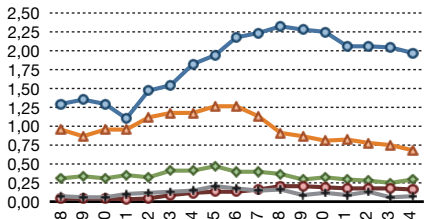

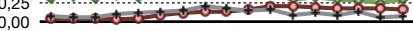

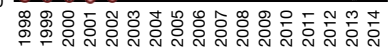

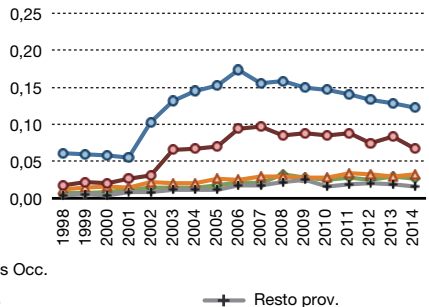

- Minicipios limítrofe

$\multimap$ Resto Vallès Occ.

Resto Barcelonès $\quad \backsim$ Resto RMB
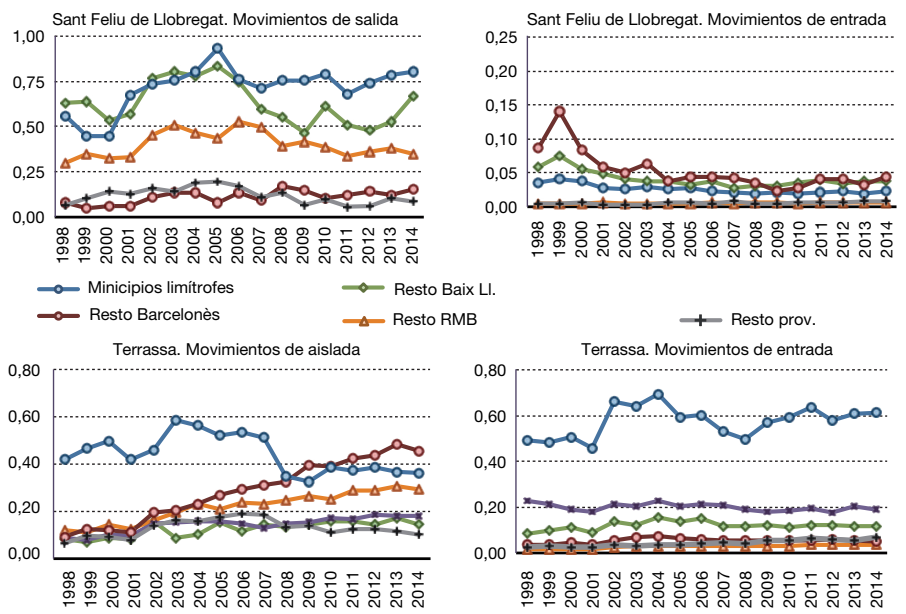

$$
\begin{aligned}
& \rightarrow \text { Terrassa } \\
& \rightarrow \text { Barcelonès }
\end{aligned}
$$$$
\leadsto \text { Resto Vallès Occ. }
$$$$
+ \text { Resto prov }
$$

Fuente: Estadística de Variaciones Residenciales y Padrón Continuo de la Población, INE (1998-2014). 
durante el periodo estudiado. Sabadell y Terrassa sobresalen como ejemplos de esta dinámica. En Sabadell, en el año 2000, tan solo el 30\% de los cambios de residencia intermunicipales tenían como destino poblaciones no limítrofes. En la actualidad, en cambio, representan casi el 60\% de todos los traslados. Por su parte, en Terrassa, los movimientos intermunicipales con destino más allá de los municipios limítrofes han pasado del 35\% al 65\%.

\section{Conclusiones y reflexiones finales}

Los patrones territoriales de la movilidad residencial en la Región Metropolitana de Barcelona han experimentado cambios profundos en los años más recientes. El nuevo escenario se aleja del modelo de desconcentración demográfica y suburbanización territorial que había sido el predominante desde la década de 1970 y que se había prolongado hasta los primeros años del siglo XXI. Los principales cambios se pueden sintetizar en los siguientes puntos:

1. Los municipios centrales ya no experimentan una desconcentración demográfica como la conocida anteriormente. No solo ha disminuido muy notablemente la intensidad de los movimientos con destino hacia la primera y la segunda coronas metropolitanas, sino que también ha aumentado la intensidad de las entradas procedentes de los ámbitos metropolitanos. Son espacios más atractivos que en la década de 1990 y comienzos del 2000 para la población de estos ámbitos. En ningún caso han dejado de desconcentrar por una disminución de la intensidad del cambio de vivienda, sino que el conjunto de la población se mueve tanto como antes, pero aumenta la movilidad intramunicipal, tal y como ha quedado probado para el caso de la ciudad de Barcelona, tanto en el caso de la población de nacionalidad española como extranjera. Así pues, cambian los patrones territoriales del fenómeno, pero no los de intensidad. Además, el centro metropolitano ha revertido el saldo migratorio negativo que registraba con el resto de municipios de Cataluña.

2. Los centros de los subsistemas residenciales metropolitanos están experimentando un proceso similar al de las poblaciones de la comarca del Barcelonès. Ha disminuido la intensidad de las salidas hacia los municipios de sus entornos metropolitanos y ha aumentado la de los movimientos hacia el centro metropolitano y hacia otros municipios de la RMB. El saldo migratorio con el resto de circunscripciones de la Región Metropolitana de Barcelona es muy similar al que se registraba durante la década de 1990 y comienzos del 2000, pero esta aparente estabilidad esconde profundos cambios en el patrón residencial de estos municipios. Si antes ganaban población procedente del centro metropolitano y perdían a favor de los municipios de su entorno, ahora ambos saldos se aproximan al equilibrio. Además, se incrementa la intensidad de los movimientos con destino a otras áreas de la RMB. Aumenta, pues, la complejidad de la dinámica residencial de los subcentros metropolitanos.

3. Los municipios medianos y pequeños de la región metropolitana dejan atrás los periodos en que crecían por migración a un ritmo extremadamente 
intenso. Incluso algunos de ellos, mayoritariamente alejados de los espacios centrales, ya presentan un saldo migratorio negativo en la relación con el resto de poblaciones metropolitanas. Se han reducido de forma muy marcada los flujos procedentes de la comarca del Barcelonès y de los subcentros metropolitanos, mientras que, en algunos casos, ha aumentado ligeramente el número de movimientos de salida.

¿Qué puede haber detrás de estos cambios? La mayoría de los puntos de inflexión observados en el presente trabajo se han producido con anterioridad al 2007, año en el que comenzó el periodo de regresión económica, aspecto que alimenta la hipótesis de un mayor peso de las razones de tipo estructural por encima de las coyunturales. En todo caso, las coyunturales podrían haber favorecido una intensificación de los procesos que se habían emprendido antes de la crisis económica. Entre los factores estructurales, es necesario hablar de la incidencia de la estructura por edades de la población en relación con la oferta y la demanda de vivienda en la Región Metropolitana de Barcelona (López-Gay y Mulder, 2012; Donat, 2012 y 2014). Las generaciones nacidas entre 1960 y 1975, los baby boomers, han sido las grandes protagonistas de la suburbanización metropolitana de Barcelona. Los nacidos a la cola de este periodo afrontaron un mercado inmobiliario más selectivo a la hora de realizar sus movimientos de emancipación residencial. En este contexto, se disparó la intensidad de los desplazamientos hacia los municipios de la segunda corona metropolitana, que son, también, los primeros que han experimentado un descenso. Además, la llegada de población de nacionalidad extranjera, en muchos casos para responder a las necesidades de construcción de vivienda, aumentó aún más la presión realizada al mercado inmobiliario. Paulatinamente, a partir de la segunda mitad de la década del 2000, son las generaciones con muchos menos efectivos, nacidas inmediatamente después del baby boom, las que atravesaron las edades de máxima movilidad residencial. Como consecuencia, la presión ejercida al mercado inmobiliario decreció, favorecida también por la desaparición de hogares por la cúspide de la pirámide que aumenta la disponibilidad de viviendas y por el freno de los flujos migratorios internacionales consecuencia de la recesión económica. En este sentido, las previsiones marcan una pauta muy clara hacia la progresiva reducción del ritmo de creación de hogares por el efecto de la propia estructura de la población. Sin contemplar la migración, la generación neta de hogares en el municipio central podría situarse en torno a 0 en 2025 (López-Gay, 2016). Más allá de la relación entre la oferta y la demanda, aparecen otros elementos vinculados al mercado de la vivienda que han variado en los últimos años. Los cambios en el sistema de tenencia, con la aparición y la consolidación del alquiler como una alternativa a la propiedad (Módenes y López-Colás, 2014), la evolución del precio de las viviendas y el endurecimiento de las condiciones para conseguir un crédito hipotecario tienen también incidencia sobre el comportamiento de la movilidad residencial. Finalmente, la proliferación de tipos de hogares más complejos y más móviles como los no familiares, así como variaciones en las 
preferencias residenciales ligadas a la revalorización de los espacios centrales, también se encuentran detrás del agotamiento del modelo de desconcentración territorial y la emergencia del patrón más complejo descrito en este artículo.

La dinámica residencial de los próximos años tendrá poco que ver con el patrón que ha predominado durante el último cuarto de siglo en la Región Metropolitana de Barcelona. Durante las últimas décadas, se ha puesto énfasis en la forma de la ciudad metropolitana, en el modo como ha crecido el territorio urbanizado en los municipios metropolitanos, se multiplicaba el número de habitantes en los municipios pequeños y medianos y abandonaban la ciudad central grandes contingentes de población. Ahora el territorio metropolitano ya está dibujado, avanza hacia una fase de madurez y comienza una etapa en la que la protagonista será la composición interna de la población de la metrópolis y no la forma territorial de la misma. La preocupación ha de basarse en conocer si la población de características similares se concentra o si se distribuye de forma heterogénea sobre el territorio metropolitano. En este sentido, una de las claves reside en las características de las personas que cambian de residencia como forma de equilibrar o de perpetuar las diferencias socioeconómicas en el territorio.

\section{Referencias bibliográficas}

Alberich, Joan (2007). La vinculació territorial de la població a Catalunya: Una aproximació a partir del cens de 2001. Departamento de Geografía de la Universitat Autònoma de Barcelona. Tesis doctoral. Mimeo.

BAYONA, Jordi y LOPEZ-GAY, Antonio (2011). «Concentración, segregación y movilidad residencial de los extranjeros en Barcelona». Documents d'Anàlisi Geogràfica [en línea], 57 (3), 381-412. $<$ https://doi.org/10.5565/rev/dag.234>.

Buzar, Stefan; Hall, Ray; Ogden, Philip (2007b). «Beyond gentrification: The demographic reurbanisation of Bologna». Environment and Planning [en línea], A, 39 (1), 64-85. $<$ https://doi.org/10.1068/a39109>.

BuZAR, Stefan; OgDen, Philip; Hall, Ray; HaAse, Annegret; Kabisch, Sigrun; STEINFÜHRER, Annet (2007a). «Splintering urban populations: Emergent landscapes of reurbanisation in four European cities». Urban Studies [en línea], 44 (4), 651-677. $<$ https://doi.org/10.1080/00420980601185544>.

Cheshire, Paul (2006). "Resurgent cities, urban myths and policy hubris: What we need to know». Urban Studies [en línea], 43 (8), 1231-1246. <https://doi. org/10.1080/00420980600775600>.

DONAT, Carles (2012). «La incidencia de las dinámicas demográficas en las necesidades residenciales y en la oferta de vivienda en la Región Metropolitana de Barcelona». Ciudad y Territorio, 44 (174), 689-705.

- (2014). L'habitatge a la regió metropolitana de Barcelona durant el cicle immobiliari 1997-2006: Una aproximació a partir de les necessitats residencials de la població. Departamento de Geografía de la Universitat Autònoma de Barcelona. Tesis doctoral. Mimeo.

FERIA, José María y SuSINO, Joaquín (2012). «Movilidad residencial y configuración metropolitana en España». En: ReQUes, Pedro y Cos, Olga de (eds.). La población 
en clave territorial: Procesos, estructuras y perspectivas de análisis. Actas XIII Congreso de la Población Española. Madrid: Ministerio de Economía y Competitividad.

FONT, Antonio (2007). «La región urbana de Barcelona: De la ciudad compacta a los territorios metropolitanos». En: InDOVINA, F. (ed.). La ciudad de baja densidad: Lógicas, gestión y contención. Barcelona: Diputació de Barcelona, 27-50.

Frey, William (2005). Metro America in the new century: Metropolitan and central city demographic shifts since 2000. Washington D.C.: The Brookings Institution. Living Cities Census Series.

GARCÍA COLL, Arlinda (2005). «Migraciones interiores y transformaciones territoriales». Papeles de Economía Española, 104, 76-91.

GiL, Fernando y BAYONA, Jordi (2012). «La dinámica urbana en España: Evolución y tipología». Papeles de Geografía, 55-56, 95-108.

KABISCH, Nadja y HAASE, Dagmar (2011). «Diversifying European agglomerations: Evidence of urban population trends for the 21st century». Population, Space and Place [en línea], 17 (3), 236-253. $<$ https://doi.org/10.1002/psp.600>.

LÓPEZ-GAY, Antonio (2008). Canvis residencials i moviments migratoris en la renovació demogràfica de Barcelona. Barcelona: Consell de Treball, Econòmic i Social de Catalunya.

- (2011). «¿Vuelve el centro?: Caracterización demográfica de los procesos de reurbanización en las metrópolis españolas». En: PujadAs, Isabel et al. (eds.). Población y espacios urbanos. Barcelona: Departament de Geografia de la UB y Grupo de Población de la AGE.

- (2014). «175 años de series demográficas en la ciudad de Barcelona: La migración como componente explicativo de la evolución de la población». Biblio 3W: Revista Bibliográfica de Geografía y Ciencias Sociales, XIX, 1098.

- (2016). «El advenimiento de las regiones maduras en España: Retos demográficos y socioeconómicos en un nuevo contexto urbano». Panorama Social, 23, 179-196.

LÓPEZ-GAY, Antonio y Mulder, Clara (2012). «Implicaciones del tamaño de las generaciones en la movilidad residencial: el caso de Barcelona». En: REQUES, Pedro y Cos, Olga de (eds.). La población en clave territorial: Procesos, estructuras y perspectivas de análisis. Actas XIII Congreso de la Población Española. Madrid: Ministerio de Economía y Competitividad.

MÓDENES, Juan Antonio (1998). Flujos espaciales e itinerarios biográficos: La movilidad residencial en el área de Barcelona. Departamento de Geografía de la Universitat Autònoma de Barcelona. Tesis doctoral. Mimeo.

Módenes, Juan Antonio y LÓPEZ-COLÁS, Julián (2014). "Cambio demográfico reciente y vivienda en España: ¿Hacia un nuevo sistema residencial?». REIS: Revista Española de Investigaciones Sociológicas [en línea], 148, 103-33 <https://doi.org/10.5477/cis/reis.148.103>.

MuÑOZ, Francesc (2007). «La producción residencial de baja densidad en la provincia de Barcelona». En: Indovina, F. (ed.). La ciudad de baja densidad: Lógicas, gestión y contención, 51-84. Barcelona: Diputació de Barcelona.

Musterd, SAKO (2006). "Segregation, urban space and the resurgent city». Urban Studies [en línea], 43 (8), 1325-1340. <https://doi.org/10.1080/00420980600776418>.

Nel.LO, Oriol (2004). "¿Cambio de siglo, cambio de ciclo?: Las grandes ciudades españolas en el umbral del siglo XXI». Ciudad y Territorio: Estudios Territoriales, $141-142,523-542$. 
NEL·LO, Oriol y DONAT, Carles (2014). «Los efectos territoriales de la crisis económica en la región metropolitana de Barcelona». En: AlberTos, J.M. y SÁnCHEZ, J.L. (eds.). Geografía de la crisis económica en España. Valencia: Servei de Publicacions, 565-609.

OGDEN, Philip E.; Hall, Ray (2000). «Households, reurbanisation and the rise of living alone in the principal French cities, 1975-90». Urban Studies [en línea], 37 (2), 367-390. <https://doi.org/10.1080/0042098002230>.

PAGÈS, Joana (2015). Es busca companyla de pis: Els pisos compartits a Barcelona, una estratègia real d'emancipació? Departamento de Geografía de la Universidad Autónoma de Barcelona. Tesis de máster. Mimeo.

PUJADAS, Isabel (2005). «De la ciudad compacta a la ciudad dispersa: Movilidad residencial en la Región Metropolitana de Barcelona, 1982-2000». XXV International Population Conference. Tours.

PUJADAS, Isabel; BAYONA, Jordi y GIL, Fernando (2014). «Pautas territoriales recientes de la movilidad residencial en las mayores regiones metropolitanas españolas: ¿Cambios coyunturales o estructurales?». En: LópEZ-GAY, Antonio et al. (eds.). XIV Congreso Nacional de Población: Cambio demográfico y socio-territorial en un contexto de crisis. Sevilla: Grupo de Población de la Asociación de Geógrafos Españoles.

Pujadas, Isabel; López Villanueva, Cristina y Bayona, Jordi (2016). "Residential mobility in the Barcelona Metropolitan Region during the present economic crisis». Portuguese Journal of Social Science [en línea], 15 (1), 91-110. <https://doi.org/10.1386/pjss.15.1.91_1>.

RECAÑO, Joaquín (2004). «Migraciones internas y distribución espacial de la población española». En: LEAL, J. Informe sobre la situación demográfica en España. Madrid: Fundación Fernando Abril Martorell, 187-228.

RÉRAT, Patrick (2012). «The New Demographic Growth of Cities: The Case of Reurbanisation in Switzerland». Urban Studies [en línea], 49 (5), 1107-1125. <https://doi.org/10.1177/0042098011408935>.

SANDER, Nikola (2014). «Internal migration in Germany, 1995-2010: New insights into east-west migration and re-urbanisation». Comparative Population Studies, 39 (2), 217-246.

STORPER, Michael y MANVILle, Michael (2006). «Behaviour, preferences and cities: Urban theory and urban resurgence». Urban Studies [en línea], 43 (8), 1247-1274. <https://doi.org/10.1080/00420980600775642>.

van den Berg, Leo, Drewett, Roy, KlaAsen, Leo H., Rossi, Angelo, \& VijverBERG, Cornelis H. (1982). Urban Europe: a study of growth and decline. Oxford: Pergamon Press.

VINUESA, Julio (1997). "El crecimiento de la población y los desequilibrios en la distribución espacial». En: PuYOL, Rafael (ed.). Dinámica de la población en España: Cambios demográficos en el último cuarto del siglo XX. Madrid: Síntesis. 